\title{
Role of Clinical Pharmacist in Promoting Patient Compliance through Assessment of Reasons for Non-Compliance and Minimum Maintenance Dose Titrations in Schizophrenic Patients
}

\author{
Mounica. Bollu ${ }^{1}$, Shaik Faizan Ali $^{1}$, Dr. Desu Brahma Srinivasa Rao ${ }^{2}$, \\ Nallani Venkataramarao ${ }^{3}$, Dr. Nalluri. Murali Krishna M.D ${ }^{4}$
}

\section{ABSTRACT}

Context: Medication non-compliance is an important area of concern in schizophrenia as it contributes to relapse and re-hospitalization of the patients. Constant advancement and study of therapeutic interventions designed to improve medication adherence and the outcome of dose titrations are required to reap the most valuable benefits from the pharmacologic treatment of schizophrenia. Aim \& Objective: The aim of the present study is to find out the reasons for drug non-compliance and the effectiveness of treatment outcomes after dose titrations in schizophrenic patients and the main objective is to educate the patient by counseling about the disease, drugs and the importance of medication adherence. Materials and Methods: This study was conducted over a period of six months. All male and female subjects of age group 30-40 receiving anti-psychotic medications for a minimum of 1 year before the study starts and who were noncompliant to the prescribed medications were included. Results: Females were prominent in the non-adherent group and males were found to be higher in Group-B. Most of the schizophrenic patients were suffering with paranoid schizophrenia, living in the urban environment and running their nuclear families. Majority of the Subjects in the non-adherent group were illiterates and unemployed, where as in the dose titration group many have completed their primary education and were employed. Compared to first generation antipsychotics, second generation antipsychotic drugs were most commonly prescribed. Almost 56.07\% do not have the support from their families. The main reasons stated by the patients to be noncompliant were difficulty in access to treatment, financial obstacles, forgetfulness. Dose titrations were made at an interval of 1 month for four antipsychotics (haloperidol, chlorpromazine, olanzapine and risperidone) and patients were benefited by the titration which was observed through the PANSS scores at each visit. Conclusion: Findings suggest that there is a need for identification and reduction of factors responsible for noncompliance. Strategies to improve adherence have the potential to reduce these costs. Dose titration shows beneficial effect to improve patient quality of life. Hence they should be implemented in clinical practice depending upon the individual patient.

\footnotetext{
${ }^{1}$ Interns (Doctor of pharmacy), Department Of Pharmacy Practice, Chalapathi Institute of Pharmaceutical Sciences, Guntur

${ }^{2}$ Professor \& Head Of The Department, Department Of Pharmacy Practice, Chalapathi Institute of Pharmaceutical Sciences, Guntur

${ }^{3}$ Professor, Department Of Pharmacy Practice, Chalapathi Institute of Pharmaceutical Sciences, Guntur

${ }^{4}$ Professor \& HOD, Department Of psychiatry, Guntur Medical College, Guntur

*Corresponding Author

(C) 2015 I M Bollu, S Ali, D Rao, V Nallani, N Krishna; licensee IJIP. This is an Open Access Research distributed under the terms of the Creative Commons Attribution License (http://creativecommons.org/licenses/by/2.0), which permits unrestricted use, distribution, and reproduction in any Medium, provided the original work is properly cited.
} 
Keywords: Schizophrenia, Non-adherence, Dose titrations, PANSS, Patient Counseling

Schizophrenia is one of the most complex and challenging of psychiatric disorders. It represents a heterogeneous syndrome of disorganized and bizarre thoughts, delusions, hallucinations, such as hearing voices, inappropriate affect and impaired psychosocial functioning. Schizophrenia typically begins in early adulthood. ${ }^{1}$

Antipsychotic medication plays an important role in schizophrenia treatment and symptom control. Effective management of schizophrenia requires continuous long-term treatment in order to keep symptoms under control and to prevent relapse. Despite the critical importance of medication, no adherence to prescribed drug treatments has been recognized as a problem worldwide and may be the most challenging aspect of treating patients with schizophrenia.

Compliance has been defined as, "the extent to which a person's behavior coincides with medical or health advice”. The word compliance has been condemned over the past 20 years because it signifies an idea of a paternalistic relationship between the physician and the patient, and therefore adherence has been adopted as a more equitable term . ${ }^{2}$

Clinicians face a complex task when trying to determine who will or will not adhere to medication treatment as prescribed.$^{3}$

Nonadherence to medication has a negative impact on the course of illness resulting in relapse, rehospitalization, longer time to remission, and attempted suicide and also contribute to the already high costs of the disease to healthcare systems.

Reducing nonadherence to antipsychotic medications has the potential to reduce psychiatric morbidity and costs of care substantially. That would improve the welfare of patients with schizophrenia and reduce the use of resources for acute psychotic episodes.

Therefore it is important to identify the key factors contributing to nonadherence in schizophrenia, and their consequences. In addition, assessing causes and consequences of nonadherence together may highlight the importance and complexity of adherence to medication in schizophrenia. However, we are not aware of any comprehensive review of both the causes and consequences of nonadherence in schizophrenia. Furthermore, there is a need for a review that investigates whether the data allow for a quantitative assessment of the specific link between nonadherence and hospitalization. ${ }^{4}$ 
Role of Clinical Pharmacist in Promoting Patient Compliance through Assessment of Reasons for NonCompliance and Minimum Maintenance Dose Titrations in Schizophrenic Patients

\section{TABLE-1: Risk factors for non-adherence in patients with schizophrenia}

Patient-related risk factors :

Socio-Demographic characteristics-age, gender and ethnicity

Illness characteristics-age at onset and duration of illness, illness severity and subtype (e.g. Paranoid schizophrenia), cognition or memory, subjective well-being.

Medication-related factors : Adverse effects, dosage, agent, route, and complexity of regimen.

General clinical factors

Drugs or alcohol consumption

Previous non adherence

Environment related risk factors

Poor family and social support,

Negative social perception of the disease

Difficulty accessing health care services

Financial burden

\section{Physician related risk factors}

Poor relationship with therapist

Poor psychoeducation and information to patients and relatives

Poor contact with the therapist

Inadequate planning of the post discharge period

\section{Treatment related risk factors}

Ineffectiveness against persistent symptoms(psychotic and negative symptoms)

Poorer adherence to oral than to intramuscular treatments.

\section{Psychopathological symptoms}

Impaired insight

Cognitive deficiency

Delusion of persecution, poisoning or grandeur

Psychotic symptoms

Negative symptoms

\section{Psychological factors:}

attitudes, beliefs and other subjective aspects

Negative attitude toward the treatment

Negative subjective response to treatment

Regarding the disease as mild and/or perceived minor benefit from treatment

Shame or stigmatization associated with the medication or the disease.

\section{EVALUATING NON-ADHERENCE}

Evaluation methods are considered to be "direct" when they offer proof that the patient has taken their medication. ${ }^{5}$ 
Table-2: Main Adherence Evaluation Methods

\begin{tabular}{|l|l|}
\hline DIRECT & INDIRECT \\
\hline \multirow{2}{*}{$\begin{array}{l}\text { Detection of the drug or its drug metabolites } \\
\text { (generally in serum or urine) }\end{array}$} & Objective \\
Direct observation of the patient & Tablet count \\
& Electronic monitoring \\
& Pharmacy records \\
\cline { 2 - 2 } & Subjective \\
& Psychometric scales \\
& Questioning the patient \\
& Questioning the relatives \\
& Clinical judgement \\
\hline
\end{tabular}

\section{ROLE OF CLINICAL PHARMACIST ${ }^{(6-21)}$}

Schizophrenia is a mental illness about $1 \%$ of people are affected with this illness in their lifetime. Non compliance is highly seen in the schizophrenic patients who are on antipsychotics which in turn results in the worsening of patient condition and attenuation of symptoms.

> Suboptimal attitudes of the patients towards mental illness and a lack of confidence highlights the need for different educational approaches to provide clinical pharmacy services to the patients

$>$ pharmacist has to Communicate with the patient and Prevents the Antipsychotic polypharmacy which inturn decreases the rates of hospitalization and mortality

$>$ As experts in pharmacotherapy, pharmacists can provide complementary skills, knowledge and attitudes to other health care professionals within a multidisciplinary team context.

$>$ Specifically pharmacists may contribute to health care teams by detecting and resolving or preventing drug related problems; helping to ensure the safe and efficacious use of medicines; providing comprehensive drug information to patients and other health care professionals;

$>$ Promoting medication adherence; and quality use of medicines.

$>$ Reinforcing primary prevention and health promotion and lifestyle modification activities in the community.

$>$ The pharmacists were able to identify people who were at high risk of the disease who had previously gone undetected, screen them and refer on to appropriate health services if required.

> Medication chart review, assessment of laboratory results and medication prescribing; and in providing education for patients and other health care professionals

$>$ Pharmacist based intervention to improve antipsychotic adherence includes the use of unit-of-use packaging, a pharmacist education session, refills reminders and notification of clinicians when patients failed to fill prescriptions. medication reminder devices, and 
using one pharmacy for all prescriptions. Most importantly, pharmacists can assist patients with schizophrenia by showing empathy, providing encouragement and support, and reminding them that adhering to their therapy is the most effective tool in managing schizophrenia.

$>$ As one of the most accessible health care professionals, pharmacists can positively impact patient outcomes by stressing the importance of medication adherence, as well as encouraging patients to maintain regular visits with their primary health care provider.

$>$ When counselling patients, pharmacists should remind them about the benefits of medication therapy and educate them regarding the potential adverse effects of the selected medication.

$>$ Successful therapy starts when patients have a thorough understanding of their therapy and the importance of therapy adherence.

\section{EDUCATING THE PATIENT AND FAMILY}

It is important for the pharmacist to accurately evaluate the patient's ability to assume responsibility for taking drugs at home. The administration of antipsychotic drugs becomes a family responsibility if the outpatient appears to be unable to manage his or her own drug therapy.

\section{The pharmacist can advise the patient or family member. It includes the following points:}

* Take regular clinical appointments when necessary because close monitoring of therapy is essential.

* Report any unusual changes or physical effects to the primary health care provider.

* Take the drug exactly as directed. Do not increase, decrease, or omit a dose or discontinue use of this drug unless directed by the physician.

* Never discontinue any of the medication unless directed by their physician,

* Do not take any non-prescription drug unless use of a specific drug has been approved by the physician.

* Inform physicians, or other medical personnel about the present antipsychotic drug therapy during consultations on other medical reasons.

* Never use alcoholic beverages, cigarette or any other illicit drugs.( If quitting smoking may be difficult for patients with schizophrenia, smoking cessation strategies such as nicotine replacement methods may be recommended by the physicians.)

* Every drug has adverse drug reactions even the antipsychotics have, but these can be controlled or prevented by life style modifications and with frequent monitoring. so clinical pharmacist has a main role in educating the patients regarding their illness, medications ,adverse drug reactions ,importance of adherence, life style modifications and also about their dietary changes. 
For eg.,

* Antipsychotics may cause orthostatic hypotension, weight gain, menstrual irregularities, sedation, dry mouth in the patients on antipsychotics.

* These ADR can trouble the patients but can be managed in a simple way like

* Weight gain which is commonly observed can be prevented by intake of sweets, beverages, fast foods and by performing regular exercises. weight should be measured monthly

* To avoid constipation, take adequate fluids and if dryness of the mouth occurs, relieve it by taking frequent sips of water, chew a hard candy, or chewing gum (preferably sugarless).

* Care should be taken while suddenly standing from supine position or always take someone's help to minimize the orthostatic hypotension.

* Change in time of administration is beneficial than withdrawing the drug In patients suffering with the problem of Sedation.

* Its better educate the patient to discuss the ADR to the physician for instance, if a patient is suffering with menstrual irregularities ,then consulting psychiatrists can adjust the dose or modify the treatment plan or he may refer the patient to gynaecologist

* Inform your primary care provider if you become pregnant or intend to become pregnant during drug therapy

* Do not drive or perform other hazardous tasks if drowsiness occurs.

\section{AIM}

$>$ The aim of the present study is to find out the improvement of patient compliance through the assessment of reasons for the drug non-compliance in schizophrenia using the Rating of medication influences (ROMI) scale, Drug attitude inventory scale and Motivation assessment scale.

$>$ This study also aimed at evaluating and comparing the effectiveness of treatment outcomes after dose titrations by using positive and negative syndrome scale (PANSS) and to improve the process of dose titration in routine clinical practice.

\section{OBJECTIVE}

- To determine the percentage of patients who reached the reduction goal with dose titrations after patient education.

- To educate the patient about the disease, drugs and the importance of medication adherence.

- To compare and analyze the effect of dose titration of antipsychotic drugs(chlorpromazine, haloperidol, olanzapine and risperidone )

- To determine the effect of counseling on the patients.

- To observe and analyze the adverse drug reactions to anti-psychotic drugs.

- To improve the quality of life 


\section{METHODOLOGY}

Study Design: A Non Experimental prospective observational study.

Study Period: This study was conducted for a period of 6 months i.e., from February 2015-july 2015.

Study Criteria :

INCLUSION CRITERIA:

- All male and female subjects of age group 30-40 who were admitted in the inpatient ward.

- Patients having the clinical diagnosis of schizophrenia at least more than 1 year prior to study.

- Patients receiving a stable dose of anti-psychotic medications for a minimum of 1 year before the study starts and who are noncompliant to the prescribed medications.

- Patients who are willing to participate and who meets the study criteria.

\section{EXCLUSION CRITERIA:}

- Patients having a known history of any major systemic illness affecting quality of life (or) likely to affect participation in the study.

- Patients receiving any excluded concomitant medications.

- Patients who are not willing to participate in the study.

\section{STUDY DESIGN}

FIGURE 1: PATIENT RECRUITMIENT AND PROGRESS THROUGH THE TRIAL

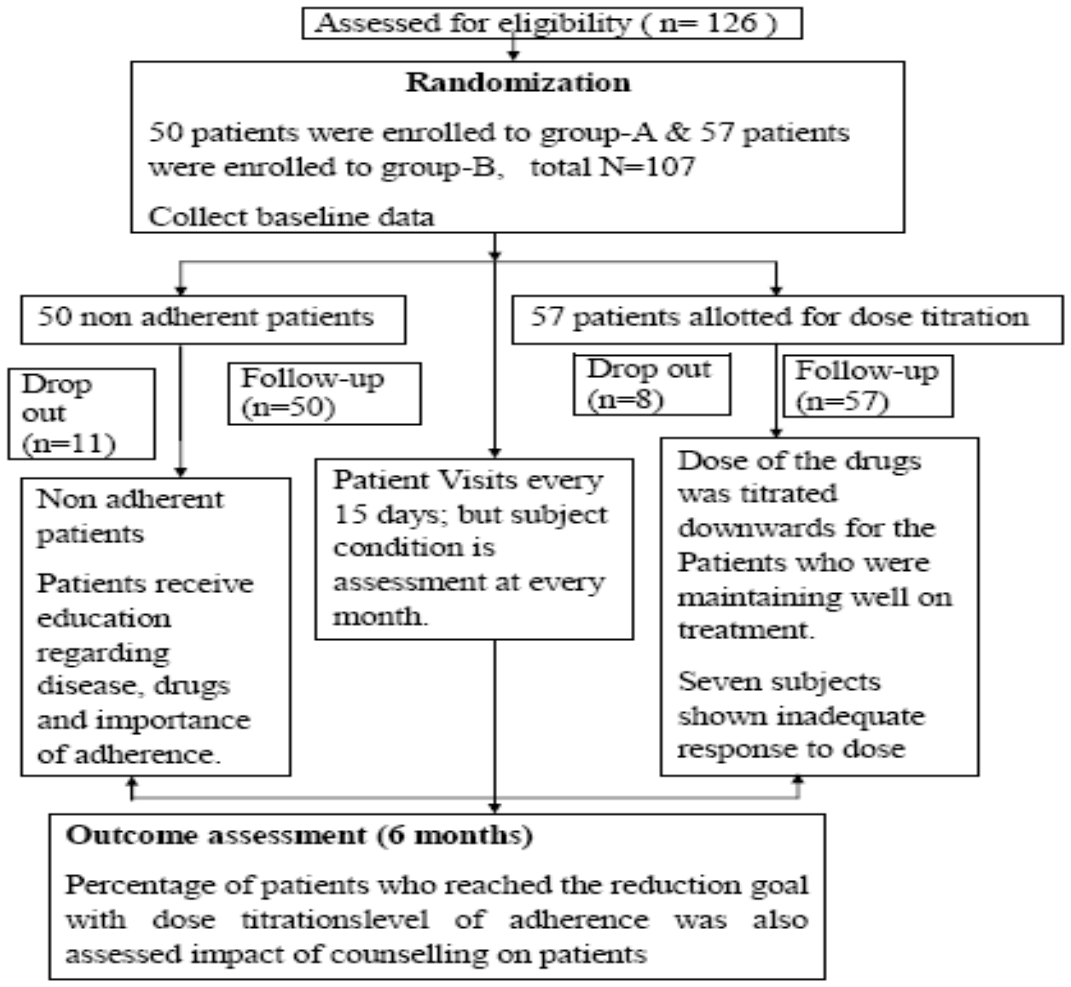




\section{OBSERVATIONS \& RESULTS}

The study sample consists of consecutive follow-up patients attending the outpatient services in our hospital for schizophrenia. After taking informed verbal consent, all patients were systematically interviewed along with the attendant and socio-demographic details were noted. The diagnosis of schizophrenia was reviewed in accordance to international classification of diseases-10 research diagnostic criteria. Patients were labeled as non-compliant if he was non adherent as per DAI scale. The attitude toward antipsychotic medication was assessed using DAI. Subjective reasons of medication compliance/non-compliance were assessed using ROMI scale .PANSS was used to assess the severity of the illness. The data was statistically analyzed using Microsoft office excel worksheet and graph pad prism.

Table-3 : Description of Study Sample

\begin{tabular}{|l|l|l|}
\hline VARIABLE & \multicolumn{2}{l|}{ NUMBER } \\
\cline { 2 - 3 } & GROUP-A & GROUP-B \\
\hline Total patients initially considered & 61 & 65 \\
\hline Patients excluded & & 8 \\
\hline Final study sample & 11 & 57 \\
\hline
\end{tabular}

Out of 126 patients,61 were grouped as non adherent but only 50 came for medication even not in the refilled dates, 11 were the drop outs because they didn't consult after consenting the study . 57 were considered for the dose titrations, among them, for 50 patients, doses were titrated for their medication and are benefited where as 7 patients didn't benefit from the dose titration, as their condition worsens after the dose titration. in this group 8 members were the dropouts.

Table-4 : Gender Wise Distribution of Study Population

\begin{tabular}{|l|l|l|}
\multicolumn{1}{c|}{$\begin{array}{l}\text { GROUP-A } \\
\text { (NON-ADHERENT) }\end{array}$} & $\begin{array}{l}\text { GROUP-B } \\
\text { (DOSE TITRATION) }\end{array}$ \\
\hline Males & 24 & 30 \\
\hline Females & 26 & 27 \\
\hline Total & 50 & 57 \\
\hline
\end{tabular}

Females were prominent in the non-adherent group and males were found to be higher in GroupB. 
Role of Clinical Pharmacist in Promoting Patient Compliance through Assessment of Reasons for NonCompliance and Minimum Maintenance Dose Titrations in Schizophrenic Patients

Graph-1 : Gender Wise Distribution of Study Population

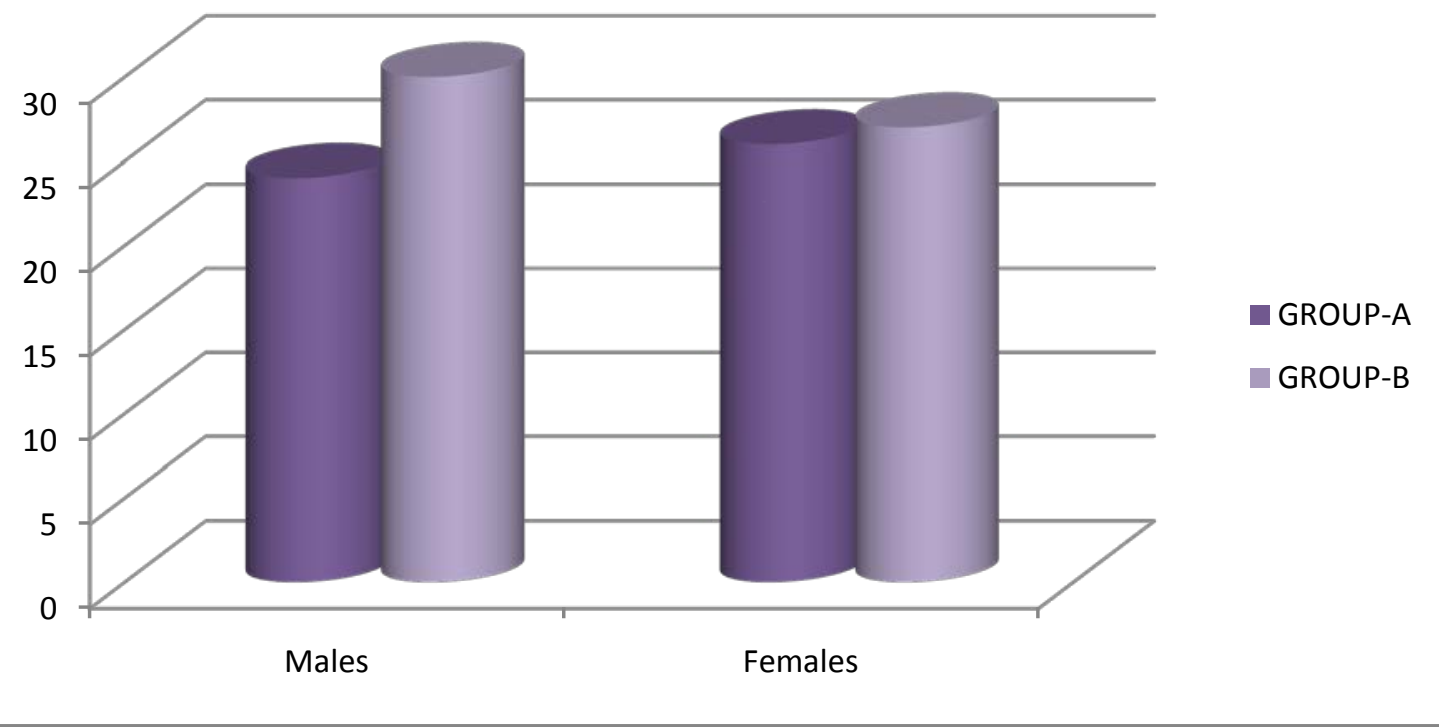

Table-5 : Characteristics of Sample of the Study

\begin{tabular}{|c|c|c|c|}
\hline CHARACTERISTIC & $\begin{array}{l}\mathrm{n}=100 \\
\text { GROUP-A } \\
\text { NUMBER (\%) }\end{array}$ & $\begin{array}{l}\text { GROUP-B } \\
\text { NUMBER (\%) }\end{array}$ & P-VALUE \\
\hline $\begin{array}{l}\text { Gender } \\
\text { Male } \\
\text { Female }\end{array}$ & \begin{tabular}{|l}
$27(48 \%)$ \\
$26(52 \%)$
\end{tabular} & $\begin{array}{l}30(52.63) \\
27(47.36)\end{array}$ & 1.000 \\
\hline $\begin{array}{l}\text { Origin } \\
\text { Urban } \\
\text { Rural }\end{array}$ & $\begin{array}{l}36(72 \%) \\
14(28 \%)\end{array}$ & $\begin{array}{l}36(63.15 \%) \\
21(36.84 \%)\end{array}$ & 0.410 \\
\hline $\begin{array}{l}\text { Marital status } \\
\text { Single } \\
\text { Married } \\
\text { Divorced }\end{array}$ & \begin{tabular}{|l}
$8(16 \%)$ \\
$33(66 \%)$ \\
$9(18 \%)$ \\
\end{tabular} & $\begin{array}{l}7(12.28 \%) \\
42(73.68 \%) \\
8(14.03 \%)\end{array}$ & 0.687 \\
\hline $\begin{array}{l}\text { Type of family } \\
\text { Nuclear } \\
\text { Joint }\end{array}$ & $\begin{array}{l}34(68 \%) \\
16(32 \%)\end{array}$ & $\begin{array}{l}35(61.40 \%) \\
22(38.59 \%)\end{array}$ & 0.546 \\
\hline $\begin{array}{l}\text { Education } \\
\text { Illiterate } \\
\text { Primary } \\
\text { Secondary } \\
\text { Graduate }\end{array}$ & $\begin{array}{l}18(36 \%) \\
15(30 \%) \\
14(28 \%) \\
3(6 \%) \\
\end{array}$ & $\begin{array}{l}8(14.03 \%) \\
21(36.84 \%) \\
17(29.82 \%) \\
11(19.29 \%)\end{array}$ & $0.025^{*}$ \\
\hline $\begin{array}{l}\text { Employment } \\
\text { Labour }\end{array}$ & $13(26 \%)$ & $10(17.54 \%)$ & \\
\hline
\end{tabular}


Role of Clinical Pharmacist in Promoting Patient Compliance through Assessment of Reasons for NonCompliance and Minimum Maintenance Dose Titrations in Schizophrenic Patients

\begin{tabular}{|l|l|l|l|}
\hline $\begin{array}{l}\text { Employed } \\
\text { Business } \\
\text { unemployed }\end{array}$ & $\begin{array}{l}14(28 \%) \\
5(10 \%)\end{array}$ & $\begin{array}{l}22(38.59 \%) \\
18(31.57 \%) \\
7(12.28 \%)\end{array}$ & $0.003^{* *}$ \\
\hline $\begin{array}{l}\text { Family income, monthly } \\
<6000\end{array}$ & $18(36 \%)$ & & \\
$6000-10000$ & $27(30 \%)$ & $13(22.80 \%)$ & \\
$>10,000$ & $8(16 \%)$ & $25(43.85 \%)$ & 0.118 \\
\hline $\begin{array}{l}\text { Care giver } \\
\text { Spouse }\end{array}$ & $26(32 \%)$ & $36(63.15 \%)$ & \\
$\begin{array}{l}\text { Parents } \\
\text { Relatives }\end{array}$ & $14(28 \%)$ & $12(21.05 \%)$ & 0.504 \\
& $10(20 \%)$ & $9(15.78 \%)$ & \\
\hline $\begin{array}{l}\text { Exercise } \\
\text { Never }\end{array}$ & & & \\
Occasionally & & & \\
$<3$ times per week & $31(\%)$ & $6(\%)$ & \\
$\geq 3$ times per week & $2(\%)$ & $13(\%)$ & \\
Daily & $8(\%)$ & $9(\%)$ & $* 0.0001$ \\
& $5(\%)$ & $5(\%)$ & \\
& $4(\%)$ & & \\
\hline
\end{tabular}

Most of the schizophrenic patients are living in the urban environment and are married and running their nuclear families.

Majority of the Subjects in the non-adherent group were illiterates and unemployed ,where as in the dose titration group many have completed their primary education and were employed, having a income of 6000-10,000.many of the patients are having their spouses as care givers followed by their parents. P-value was calculated by using chi-square test ,to identify the significance between the two study groups.

\section{Graph-2 : Distribution of Study Population by Marital Status}

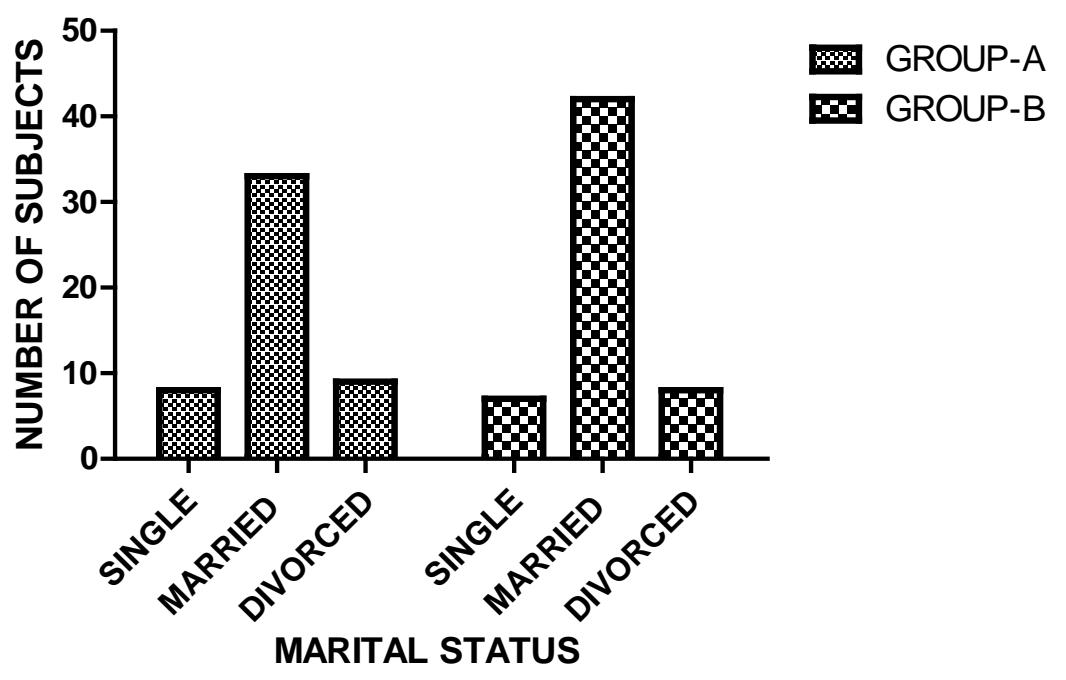


Role of Clinical Pharmacist in Promoting Patient Compliance through Assessment of Reasons for NonCompliance and Minimum Maintenance Dose Titrations in Schizophrenic Patients

Graph -3 : Distribution of Study Population by Educational Status

P-VALUE : 0.025

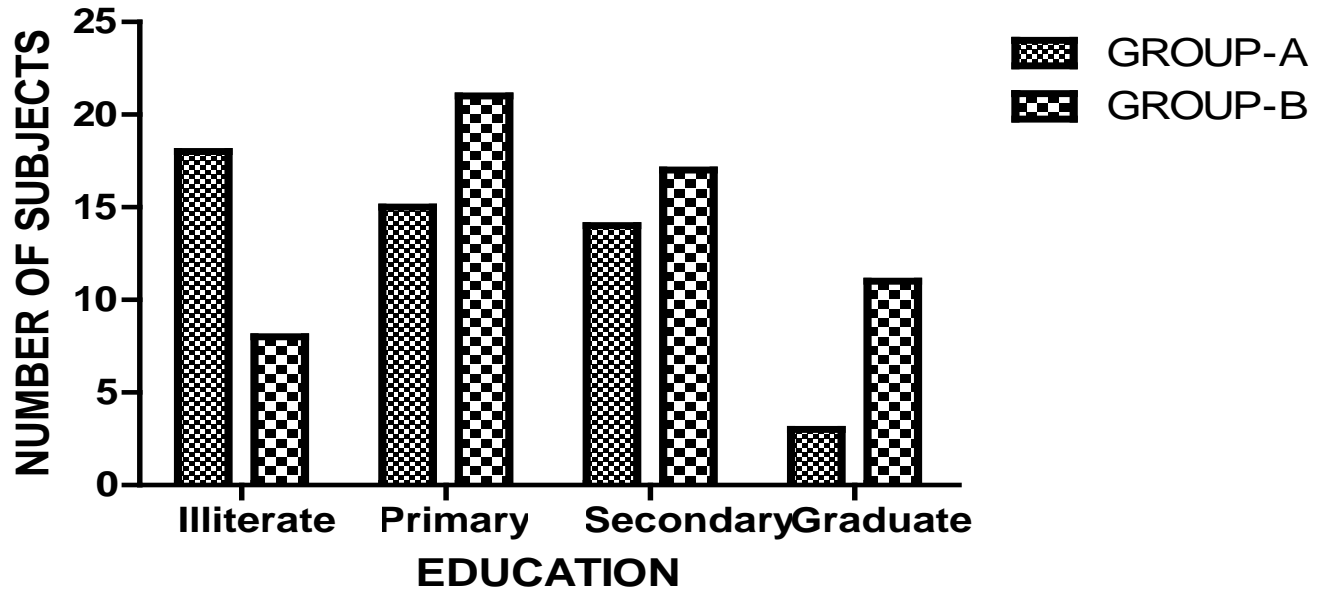

Graph - 4: Distribution Of Study Population By Their Employement Status

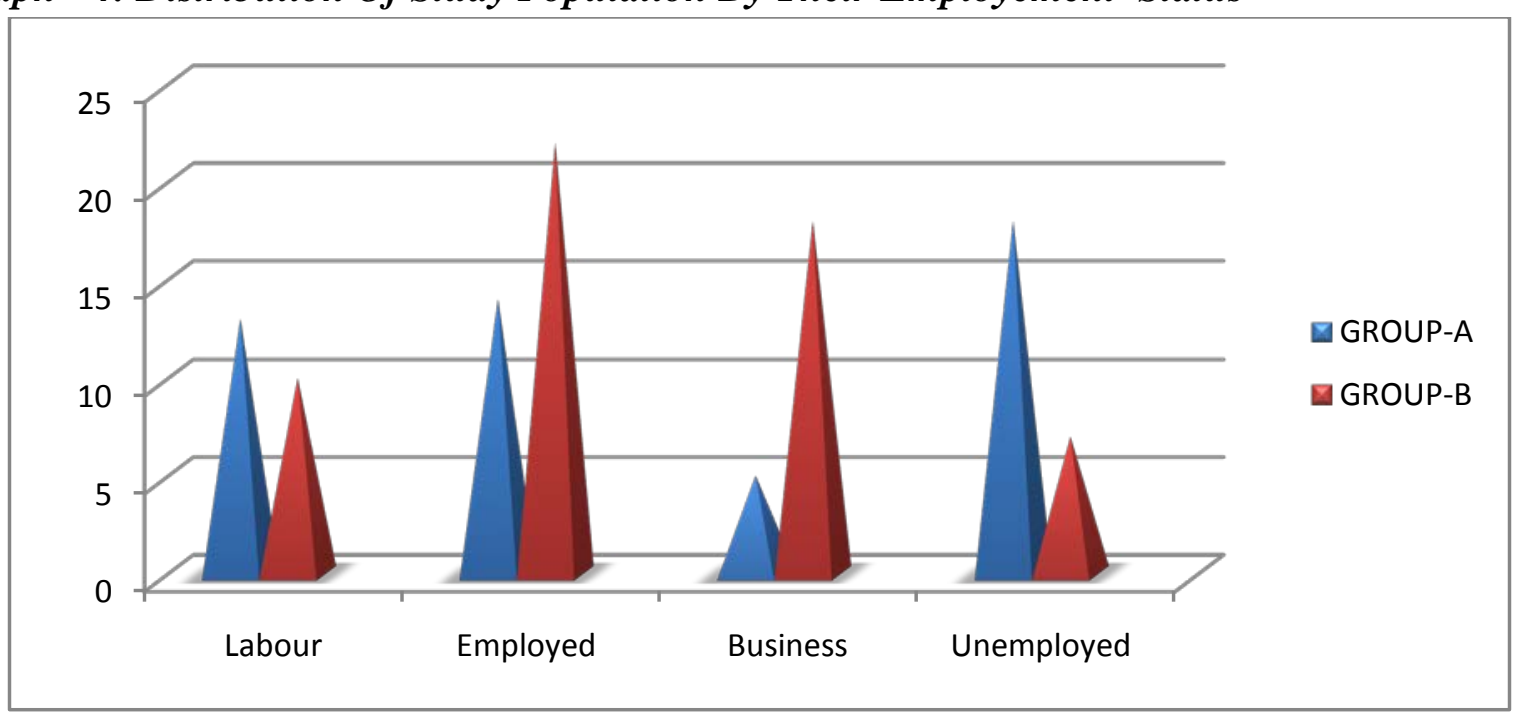

Table-6: Clinical Variables of the Patients

\begin{tabular}{|l|l|l|l|}
\hline VARIABLE & $\begin{array}{l}\text { N=100 } \\
\text { GROUP-A }\end{array}$ & \multicolumn{1}{c|}{ GROUP-B } & \multicolumn{1}{c|}{ P-VALUE } \\
\hline $\begin{array}{l}\text { Schizophrenia type } \\
\text { Paranoid }\end{array}$ & $32(64 \%)$ & $41(71.92 \%)$ & \\
Catatonic & $11(22 \%)$ & $8(14.03 \%)$ & 0.6502 \\
Disorganized & $4(8 \%)$ & $4(7.01 \%)$ & \\
Undifferentiated & $1(2 \%)$ & $3(5.26 \%)$ & \\
Residual & $2(4 \%)$ & $1(1.75 \%)$ & \\
\hline
\end{tabular}


Role of Clinical Pharmacist in Promoting Patient Compliance through Assessment of Reasons for NonCompliance and Minimum Maintenance Dose Titrations in Schizophrenic Patients

\begin{tabular}{|c|c|c|c|}
\hline $\begin{array}{l}\text { Medications added } \\
\text { Anti-cholinergics } \\
\text { Sedatives/Anxiolytics } \\
\text { Antidepressants } \\
\text { Vitamin supplements } \\
\text { Mood stabilizers } \\
\text { Antacids } \\
\text { Anticonvulsants }\end{array}$ & $\begin{array}{l}42(84 \%) \\
33(66 \%) \\
13(26 \%) \\
38(76 \%) \\
16(32 \%) \\
25(50 \%) \\
7(14 \%)\end{array}$ & $\begin{array}{l}53(92.9 \%) \\
26(45.61 \%) \\
14(24.5 \%) \\
38(66.6 \%) \\
15(26.3 \%) \\
23(40.3 \%) \\
6(10.5 \%)\end{array}$ & 0.886 \\
\hline $\begin{array}{l}\text { Baseline antipsychotic medications } \\
\text { Olanzapine alone } \\
\text { Risperidone alone } \\
\text { Combination of olanzapine and risperidone } \\
\text { Risperidone and haloperidol } \\
\text { Olanzapine and haloperidol } \\
\text { Olanzapine and chlorpromazine } \\
\text { Risperidone and chlorpromazine } \\
\text { Risperidone,olanzapine and chlorpromazine } \\
\text { Olanzapine,haloperidol,risperidone }\end{array}$ & $\begin{array}{l}3(0.06 \%) \\
5(10 \%) \\
6(12 \%) \\
5(10 \%) \\
9(18 \%) \\
3(6 \%) \\
2(4 \%) \\
7(14 \%) \\
10(20 \%)\end{array}$ & $\begin{array}{l}4(7.01 \%) \\
2(3.5 \%) \\
15(26.3 \%) \\
7(12.2 \%) \\
8(14.03 \%) \\
13(22.8 \%) \\
3(5.26 \%) \\
2(3.5 \%) \\
3(5.26 \%)\end{array}$ & $0.0191 *$ \\
\hline $\begin{array}{l}\text { Number of hospitalizations } \\
0 \\
1-5 \\
>5\end{array}$ & $\begin{array}{l}3(6 \%) \\
12(24 \%) \\
35(70 \%)\end{array}$ & $\begin{array}{l}\text { 19(33.3\%) } \\
32(56.1 \%) \\
6(10.5 \%)\end{array}$ & $<0.0001^{* * *}$ \\
\hline $\begin{array}{l}\text { Duration of illness,years } \mathbf{n}(\mathbf{\%}) \\
0-5 \\
6-10 \\
11-15 \\
>15\end{array}$ & $\begin{array}{l}5(10 \%) \\
10(20 \%) \\
12(24 \%) \\
23(46 \%)\end{array}$ & $\begin{array}{l}18(31.5 \%) \\
25(43.8 \%) \\
6(10.5 \%) \\
8(14.03 \%)\end{array}$ & $<0.0001^{* * *}$ \\
\hline $\begin{array}{l}\text { Exacerbations n(\%) } \\
1-2 \\
3-5 \\
6-9 \\
>9\end{array}$ & $\begin{array}{l}9(18 \%) \\
14(28 \%) \\
19(38 \%) \\
8(16 \%)\end{array}$ & $\begin{array}{l}25(43.8 \%) \\
18(31.5 \%) \\
10(17.5 \%) \\
4(7.01 \%)\end{array}$ & $0.0083^{* *}$ \\
\hline Relapses & 50 (100\%) & $31(54.3 \%)$ & \\
\hline $\begin{array}{l}\text { Medication } \\
\text { First generation antipsychotics } \\
\text { Second generation antipsychotics }\end{array}$ & $\begin{array}{l}36(72 \%) \\
50(100 \%)\end{array}$ & $\begin{array}{l}36(63.15 \%) \\
57(100 \%)\end{array}$ & 0.667 \\
\hline Insight & $22(44 \%)$ & 38 (66.6\%) & \\
\hline
\end{tabular}


In the present study, we found that many of the patients were suffering with paranoid schizophrenia than the other types. Anticholinergics and vitamin supplements were the main medications added along with the antipsychotics for the patients. Combination of olanzapine and risperidone was most commonly used. Patients in the non-adherent group were hospitalized many times compared to group-B. Non-adherent patients were suffering with the disease from many years and have experienced the exacerbations greater when compared to dose titration group patients. Compared to first generation antipsychotics, second generation antipsychotic drugs were most commonly prescribed.

\section{Graph-5 : Medications Added to the Patients}

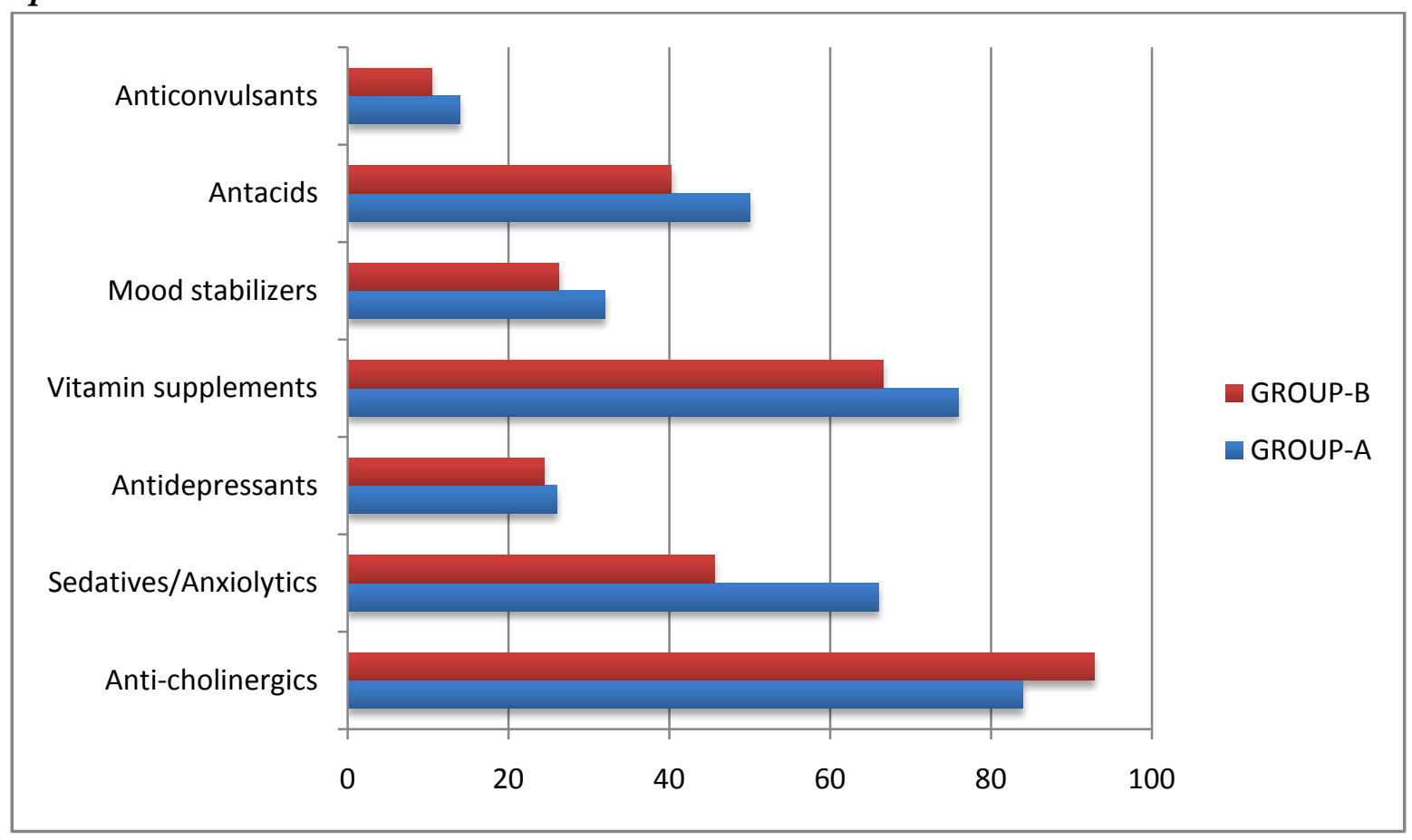

Graph - 6 : Number of Hospitalizations for Schizpohrenia in General Hospital Per 107 Patients

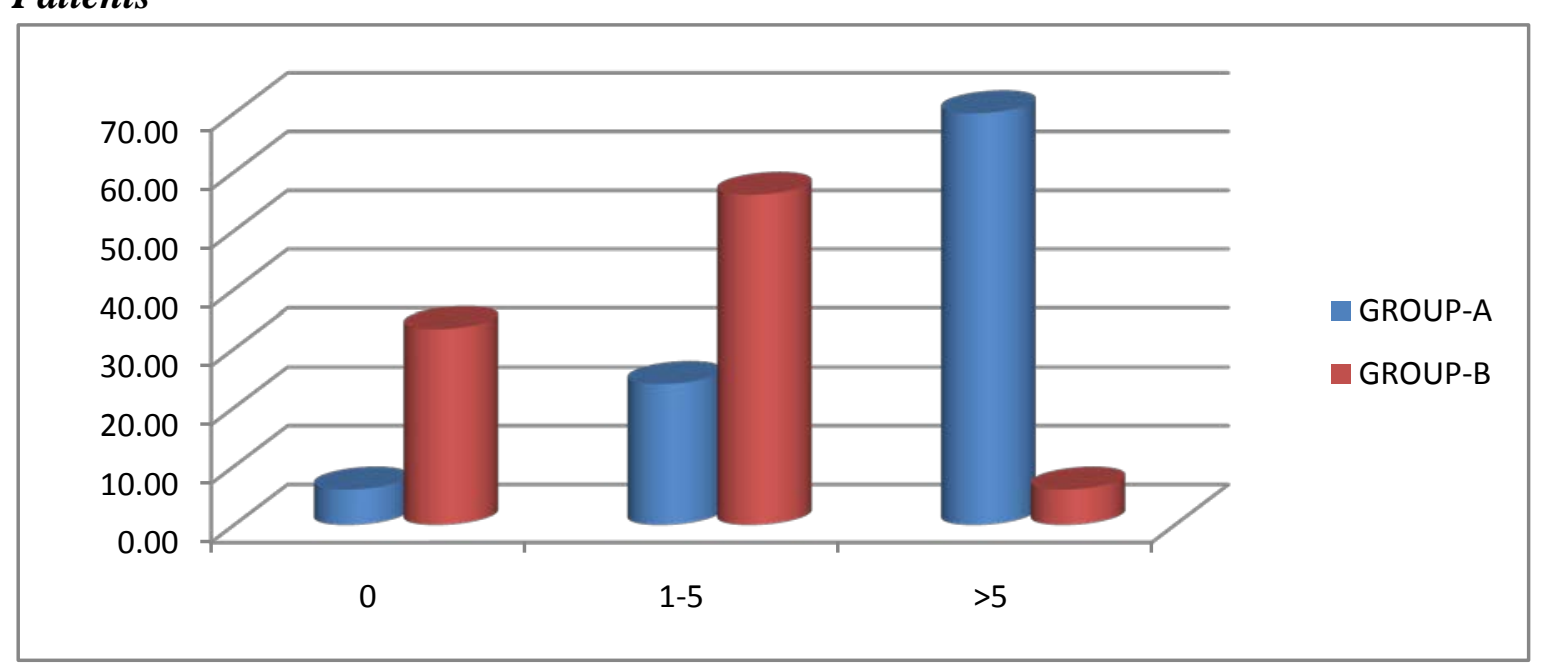


Role of Clinical Pharmacist in Promoting Patient Compliance through Assessment of Reasons for NonCompliance and Minimum Maintenance Dose Titrations in Schizophrenic Patients

Graph-7 : Number of Exacerbations Observed in Study Population

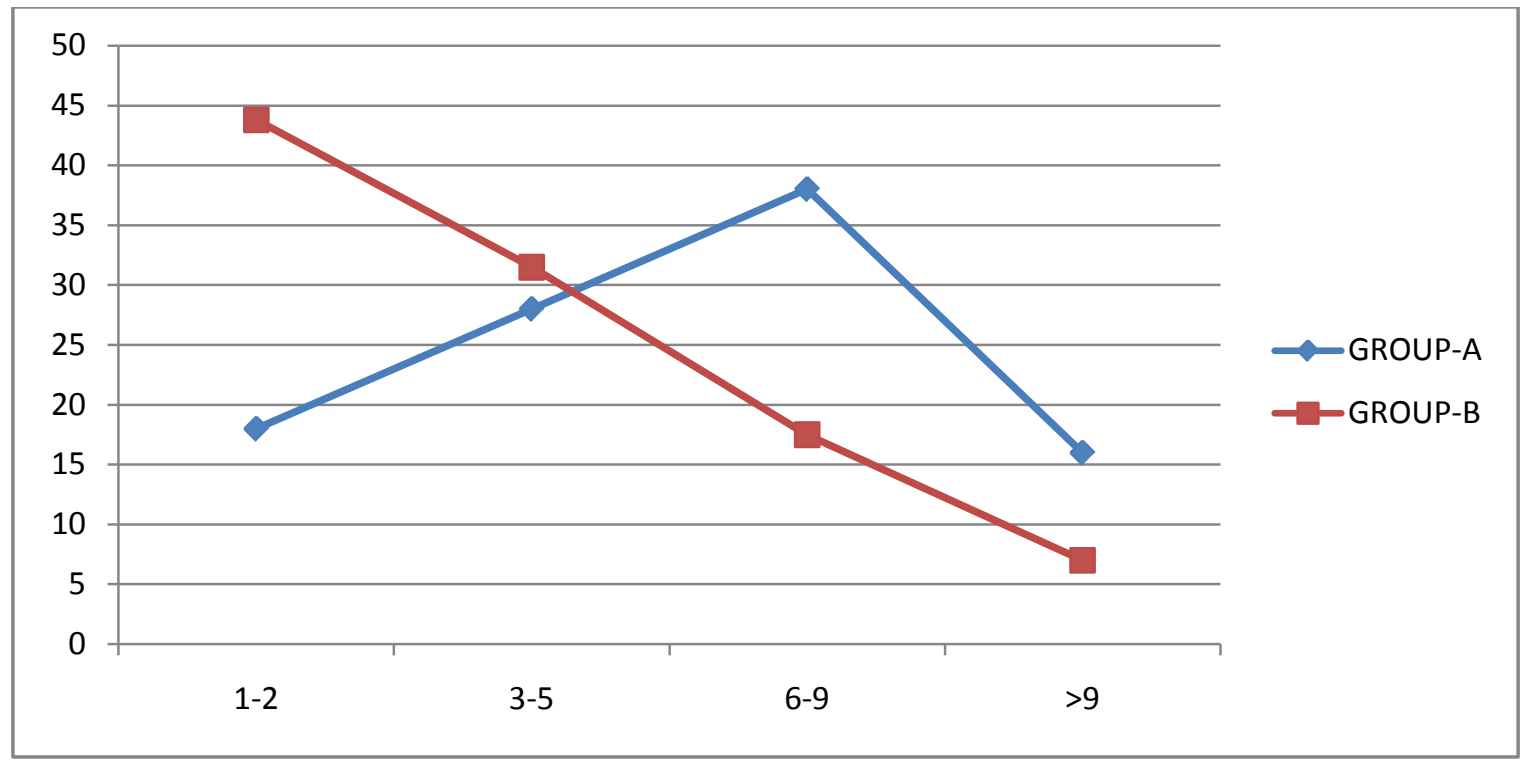

Table-7: Antipsychotic Medication Monitored Across the Study Period

\begin{tabular}{|c|c|c|}
\hline \multirow[t]{2}{*}{ MEDICATION } & \multicolumn{2}{|c|}{ PATIENTS (n=107) } \\
\hline & $\mathbf{N}$ & (\%) \\
\hline Haloperidol & 42 & $39.2 \%$ \\
\hline Chlorpromazine & 30 & $28.03 \%$ \\
\hline Olanzapine & 83 & $77.5 \%$ \\
\hline Risperidone & \begin{tabular}{|ll}
67 \\
\end{tabular} & $62.6 \%$ \\
\hline
\end{tabular}

This table suggest that the majority (77.5\%) of the patients were on the medication olanzapine

Graph-8: Antipsychotic Medication Monitored Across the Study Period

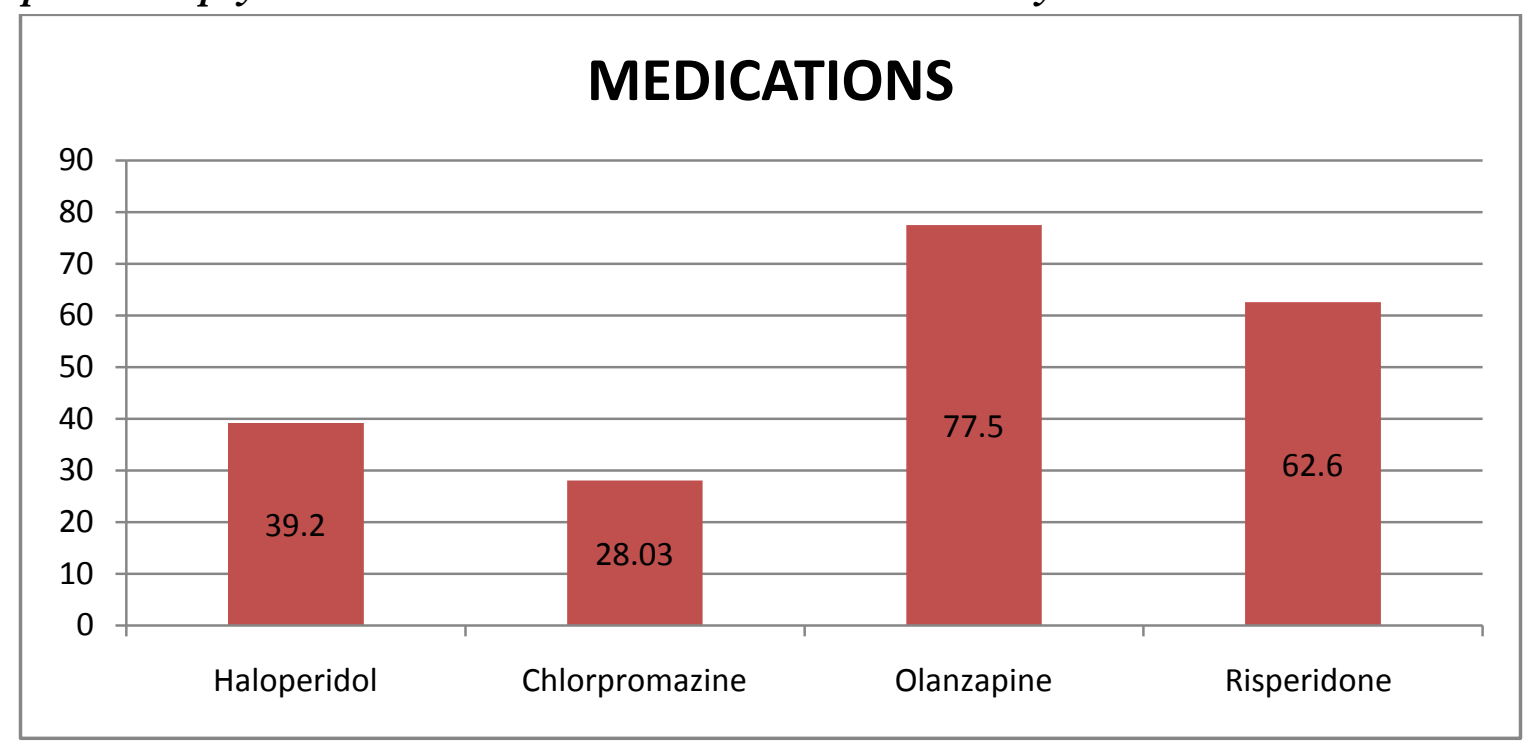


Role of Clinical Pharmacist in Promoting Patient Compliance through Assessment of Reasons for NonCompliance and Minimum Maintenance Dose Titrations in Schizophrenic Patients

Table-8: Family History of Study Population

\begin{tabular}{|l|l|}
\hline FAMILY HISTORY & $\begin{array}{l}\text { NUMBER OF PATIENTS } \\
\text { (PERCENTAGE) }\end{array}$ \\
\hline Yes & $61(57 \%)$ \\
\hline No & $29(27.10 \%)$ \\
\hline Not known & $15(14.01 \%)$ \\
\hline Total & 107 \\
\hline
\end{tabular}

In the present study, it was found that Almost $57 \%$ of the subjects have the family history of schizophrenia.

Graph-9: Family History of Study Population

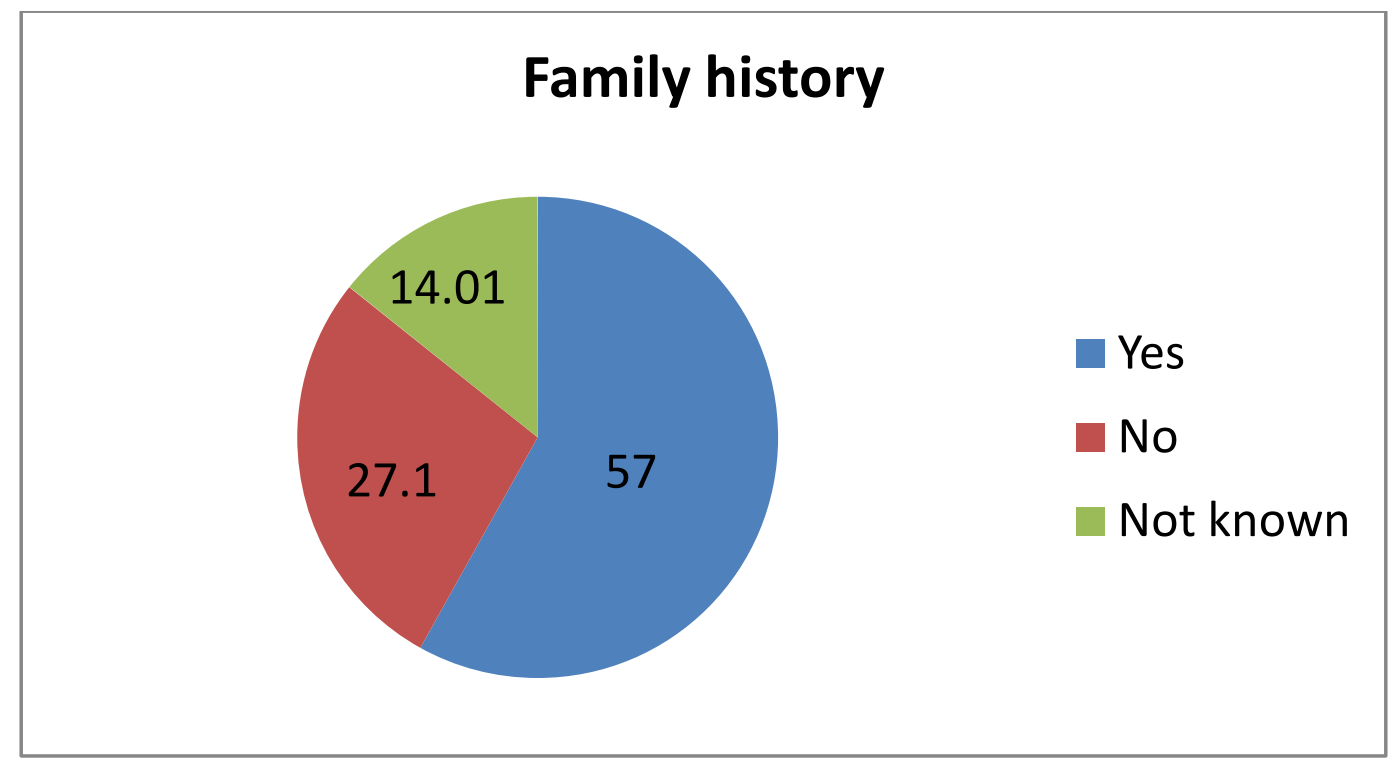

Table-9: Family Support of Study Population

\begin{tabular}{|l|l|}
\hline FAMILY SUPPORT & $\begin{array}{l}\text { NUMBER OF PATIENTS } \\
\text { (PERCENTAGE) }\end{array}$ \\
\hline Yes & $47(43.92 \%)$ \\
\hline No & $60(56.07 \%)$ \\
\hline Total & 107 \\
\hline
\end{tabular}

From the study, it was observed that $56.07 \%$ of the study population do not have the support from their families. 
Graph-10: Family Support of Study Population

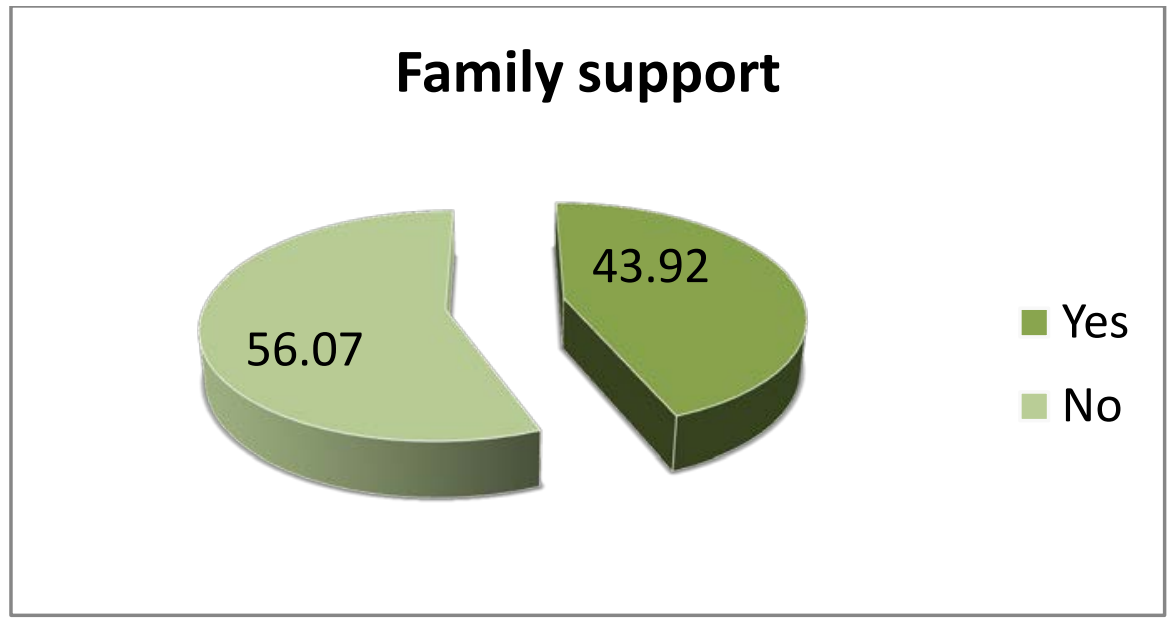

Table-10: Attitude of Patient towards Medication

\begin{tabular}{|l|l|l|}
\hline DAI & COMPLIANT & NON-COMPLIANT \\
\hline Positive domain & $6.86 \pm 3.0$ & $2.98 \pm 1.43$ \\
\hline Negative domain & $2.5 \pm 1.44$ & $7.5 \pm 3.67$ \\
\hline Total score & $6.08 \pm 2.02$ & $4.98 \pm 2.17$ \\
\hline
\end{tabular}

Analysis of the relationship between subjective attitude and reasons for compliance only revealed a direct relationship between the score obtained on the DAI Scale and the compliance subscale of ROMI.

The DAI is one of the most common measures used to assess attitude or adherence rating scales. positive attitude towards medication ,as measured by the DAI is associated with significantly higher adherence rates. The attitude towards treatment in patients has been additionally related to factors such as employment status, duration of untreated schizophrenia, disease severity ,treatment response, hospital profile and therapeutic alliance with the medical staff.

Table-11: Various Reasons of Compliance Using Romi Scale

\begin{tabular}{|c|c|c|c|}
\hline REASONS & $\begin{array}{l}\text { MALES } \\
(\mathrm{N}=30)\end{array}$ & $\begin{array}{l}\text { FEMALES } \\
(\mathrm{N}=27)\end{array}$ & $\begin{array}{l}\text { TOTAL } \\
(\%)\end{array}$ \\
\hline $\begin{array}{l}\text { Positive relation with } \\
\text { psychiatrist }\end{array}$ & 7 & 11 & $18(31.57)$ \\
\hline Perceived daily benefit & 14 & 16 & $30(52.63)$ \\
\hline Family Pressure/force & 21 & 22 & $43(75.43)$ \\
\hline Relapse prevention & 27 & 24 & 51(89.47) \\
\hline Fear of hospitalization & 18 & 21 & $39(68.42)$ \\
\hline Positive family belief & 12 & 11 & $23(40.35)$ \\
\hline Desire to be normal & 23 & 19. & $42(73.68)$ \\
\hline Supervision & 17 & 15 & $32(56.14)$ \\
\hline Fulfilling life ideals & 14 & 13 & $27(47.36)$ \\
\hline
\end{tabular}


Role of Clinical Pharmacist in Promoting Patient Compliance through Assessment of Reasons for NonCompliance and Minimum Maintenance Dose Titrations in Schizophrenic Patients

The main reason stated by the patient to be compliant was to prevent the relapses followed by family pressure.

\section{Graph-11: Various Reasons of Compliance}

\section{REASONS OF COMPLIANCE}

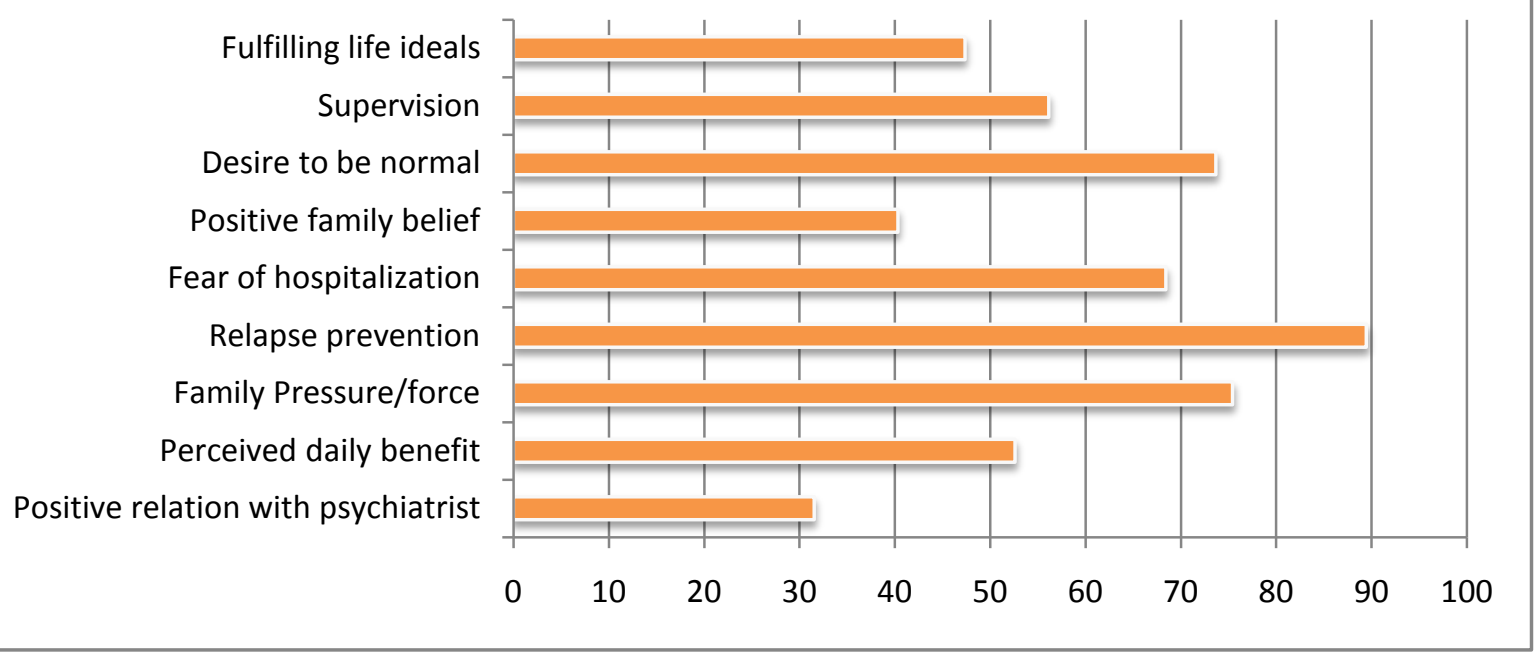

Table-12: Various Reasons of Non Compliance Using Romi Scale

\begin{tabular}{|l|l|l|l|}
\hline REASONS & $\begin{array}{l}\text { MALES } \\
(\mathbf{N}=\mathbf{2 4})\end{array}$ & $\begin{array}{l}\text { FEMALES } \\
(\mathbf{N = 2 6 )}\end{array}$ & TOTAL (\%) \\
\hline Access to treatment problems & 19 & 21 & $40(80 \%)$ \\
\hline Financial obstacles & 15 & 18 & $33(66 \%)$ \\
\hline Desires rehospitalization & 4 & 7 & $11(22 \%)$ \\
\hline Distressed by adverse drug reactions & 17 & 15 & $32(64 \%)$ \\
\hline Interference with life ideals & 11 & 9 & $20(40 \%)$ \\
\hline Forgetfulness & 13 & 16 & $29(58 \%)$ \\
\hline No perceived daily benefit & 18 & 14 & $32(64 \%)$ \\
\hline Denial of illness & 12 & 10 & $22(44 \%)$ \\
\hline $\begin{array}{l}\text { General opposition to use of medication } \\
\text { by friends/family }\end{array}$ & 7 & 4 & $11(22 \%)$ \\
\hline Medication currently unnecessary & 5 & 3 & $8(16 \%)$ \\
\hline Stigma with treatment & 11 & 8 & $19(38 \%)$ \\
\hline Substance abuse & 4 & 1 & $5(10 \%)$ \\
\hline Stigma over illness & 7 & 5 & $12(24 \%)$ \\
\hline Negative relation with physician & 3 & 1 & $4(8 \%)$ \\
\hline
\end{tabular}


$80 \%$ of the patients have the difficulty in access to treatment , $66 \%$ became non-complaint because of their financial obstacles and $58 \%$ were not taking their medications due to forgetfulness.

\section{Graph-12: Various Reasons of Non Compliance}

\section{REASONS OF NON COMPLIANCE}

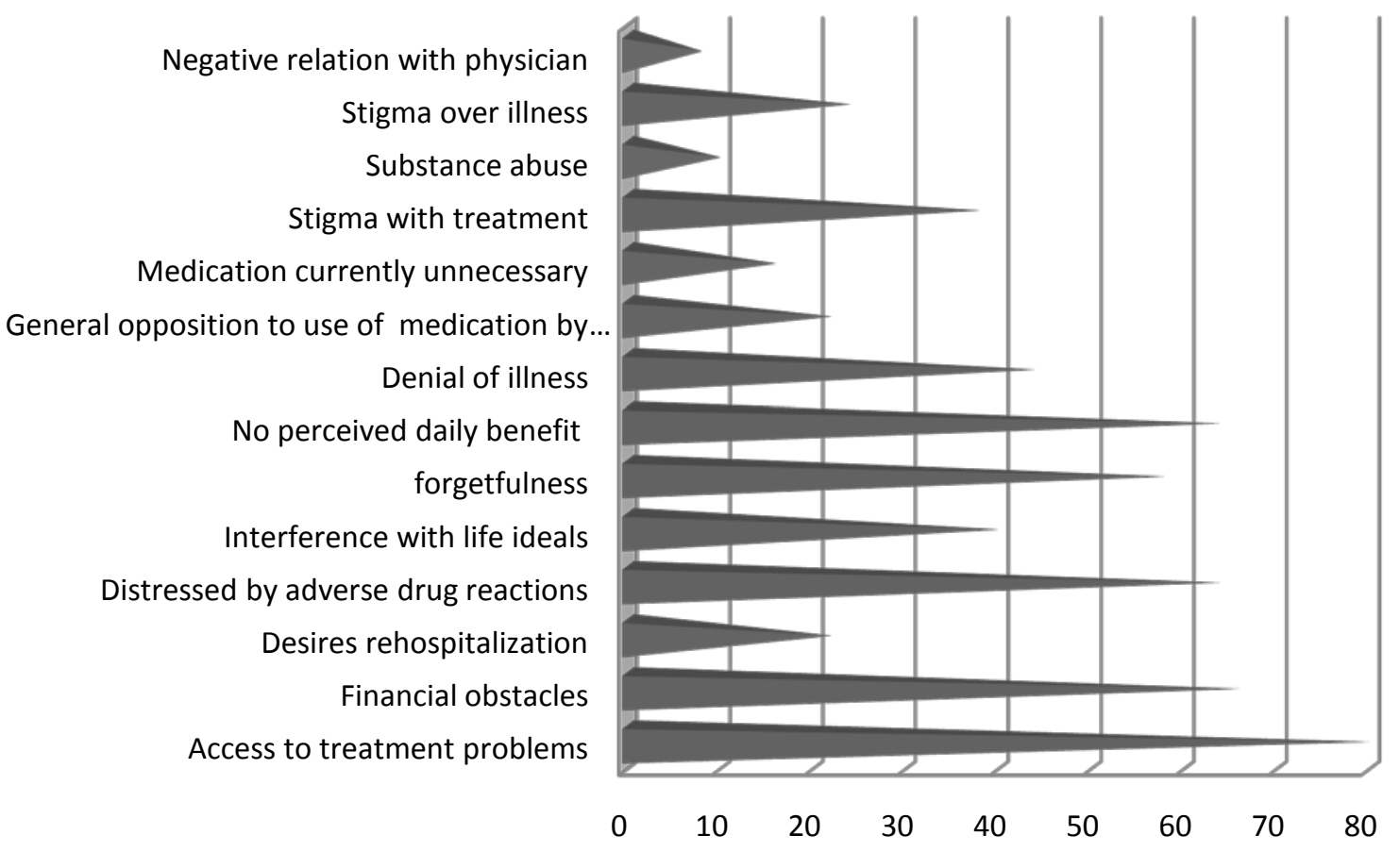

CAUSALITY OF ADR BY NARANJO'S SCALE: ADR'S are categorized by score in the Naranjo Adverse Drug Reaction Probability Scale. In our study, 3 definite ADR's were observed which includes sedation(57\%),skin pigmentation (18\%) \& dystonia (33\%).19 ADR's was categorized as probable which consists of events like hypotension (17\%), palpitations (11\%), weight gain (23\%), orthostatic hypotension (15\%), bleeding from rectum (5\%), akathisia (24\%), xerostomia(35\%), vomiting(7\%), dizziness(51\%), constipation (38\%), tremor (44\%), abdominal distension (7\%), galactorrhoea (8\%), excessive salivation(12\%), blurred vision (5\%), parkinsonism (18\%), hypothyroidism (7\%), diabetes (8\%) and somnolence (11\%). 15 were observed which on assessment with naranjo's scale, categorised as possible ADR's which include headache (17\%), sexual dysfunction (6\%), odynophagia (4\%), T.corporis infection (2\%), polymenorrhea (24\%), delusion of infidelity (1\%), erythroderma (3\%), chestpain(14\%),intertrigo (1\%), burningmicturition (17\%), amenorrhea (15\%), menorrhagia (4\%), gastritis (7\%), hypertension (13\%), paronychia (3\%). 
Role of Clinical Pharmacist in Promoting Patient Compliance through Assessment of Reasons for NonCompliance and Minimum Maintenance Dose Titrations in Schizophrenic Patients

Table-13: Comparision of Mean Scores of Mmas-8 between Visits

\begin{tabular}{|l|l|l|l|l|l|}
\hline $\begin{array}{l}\text { ASSESSMENT } \\
\text { PARAMETER }\end{array}$ & BASELINE & VISIT 1 & VISIT 2 & VISIT 3 & VISIT 4 \\
\hline $\begin{array}{l}\text { MMAS-8 } \\
\text { SCORE }\end{array}$ & $5.44 \pm 1.68$ & $3.94 \pm 1.42$ & $2.46 \pm 1.32$ & $1.28 \pm 1.12$ & $0.52 \pm 0$ \\
\hline
\end{tabular}

Graph-13: Comparision of Mean Scores of Mmas-8 between Visits

\section{MMAS-8 SCORE}

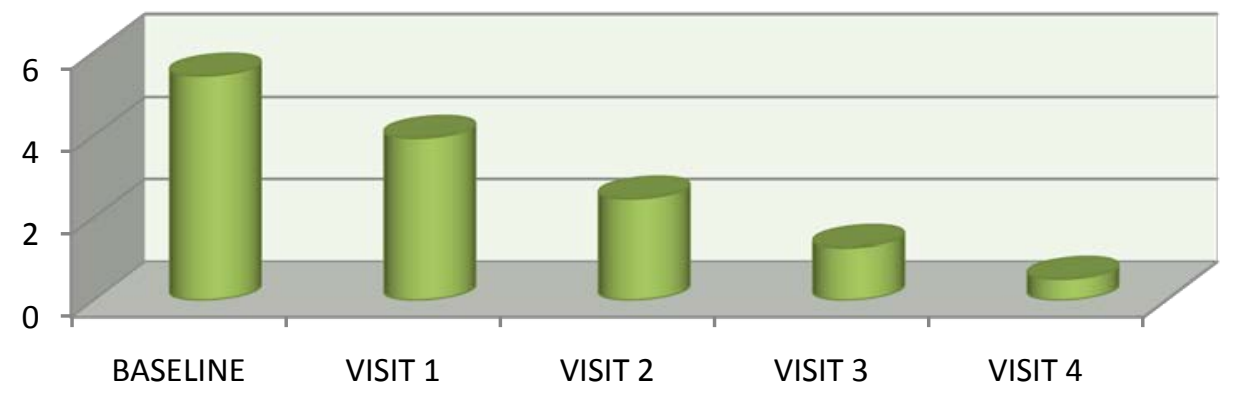

Table-14: Discontinuation Rates in Patients with Schizophrenia

\begin{tabular}{|l|l|l|l|l|}
\hline $\begin{array}{l}\text { Reason for } \\
\text { discontinuation }\end{array}$ & $\begin{array}{l}\text { Olanzapine } \\
(\mathbf{n = 8 3 )} \\
\mathbf{N}(\%)\end{array}$ & $\begin{array}{l}\text { Risperidone } \\
(\mathbf{n = 6 7 )} \\
\mathbf{N}(\%)\end{array}$ & $\begin{array}{l}\text { Haloperidol } \\
(\mathbf{n}=\mathbf{4 2}) \\
\mathbf{N}(\%)\end{array}$ & $\begin{array}{l}\text { Chlorpromazine } \\
(\mathbf{n}=\mathbf{3 0}) \\
\mathbf{N}(\%)\end{array}$ \\
\hline Lack of tolerability & $11(13.2 \%)$ & $15(22.3 \%)$ & $24(57.1 \%)$ & $10(33.3 \%)$ \\
\hline Lack of efficacy & $7(8.43 \%)$ & $13(19.4 \%)$ & $5(11.9 \%)$ & $3(10 \%)$ \\
\hline
\end{tabular}

Table-15: Dosing Comparision of Antipsychotic Drugs in Patients with Schizophrenia from the Study

\begin{tabular}{|l|l|l|l|l|}
\hline Dose & Haloperidol & Chlorpromazine & Risperidone & Olanzapine \\
\hline $\begin{array}{l}\text { Dose } \\
\text { range,mg/day }\end{array}$ & $5-15 \mathrm{mg} /$ day & $400-1200 \mathrm{mg} /$ day & $2-6 \mathrm{mg} /$ day & $10-20 \mathrm{mg} /$ day \\
\hline $\begin{array}{l}\text { Mean dose } \\
\text { mg/day (total no } \\
\text { of patients) }\end{array}$ & $7.5(42)$ & $250(30)$ & $5(67)$ & $15(83)$ \\
\hline $\begin{array}{l}\text { Maximum dose } \\
\text { received (mg/day) }\end{array}$ & 10 & 400 & 8 & 20 \\
\hline $\begin{array}{l}\text { Number reaching } \\
\text { maximum dose } \\
\text { (\%) }\end{array}$ & $31(73.8) \%$ & $12(40 \%)$ & $48(71.6 \%)$ & $75(90.3 \%)$ \\
\hline
\end{tabular}


Role of Clinical Pharmacist in Promoting Patient Compliance through Assessment of Reasons for NonCompliance and Minimum Maintenance Dose Titrations in Schizophrenic Patients

Table-16: Initial Dose and Titration Schedule for the Schizophrenic Patients with No Complicating Condition Affecting Dosing

\begin{tabular}{|l|l|l|l|}
\hline $\begin{array}{l}\text { ANTIPSYCHOTIC } \\
\text { MEDICATION }\end{array}$ & $\begin{array}{l}\text { USUAL STARTING } \\
\text { DOSE } \\
\text { (MG/DAY),RANGE }\end{array}$ & $\begin{array}{l}\text { INTERVAL } \\
\text { BETWEEN DOSE } \\
\text { DECREASE }\end{array}$ & $\begin{array}{l}\text { USUAL DOSE } \\
\text { DECREMENT,MG }\end{array}$ \\
\hline Haloperidol & $10(5-15 \mathrm{mg})$ & 1 month & $5 \mathrm{mg}$ \\
\cline { 1 - 2 } Chlorpromazine & $200(400-1200 \mathrm{mg})$ & & $50 \mathrm{mg}$ \\
\cline { 1 - 2 } Risperidone & $4(2-6 \mathrm{mg})$ & & $1 \mathrm{mg}$ \\
\cline { 1 - 2 } Olanzapine & $20(10-20 \mathrm{mg})$ & & $5 \mathrm{mg}$ \\
\hline
\end{tabular}

Table-17: Mean Panss Positive Score, Negative Score, and General Psychopathology Score For Patients At Each Visit

\begin{tabular}{|c|c|c|c|c|c|c|}
\hline \multirow{2}{*}{ Score,mean (SD) } & \multicolumn{6}{|l|}{ In treatment } \\
\hline & BASELINE & VISIT 1 & VISIT 2 & VISIT 3 & VISIT 4 & VISIT 5 \\
\hline PANSS positive & $\begin{array}{c}36.28 \\
(7.78)\end{array}$ & $\begin{array}{l}33.02 \\
(5.91)\end{array}$ & $\begin{array}{l}32.68 \\
(5.73)\end{array}$ & $\begin{array}{l}30.42 \\
(7.05)\end{array}$ & $\begin{array}{l}25.18 \\
(9.06)\end{array}$ & $\begin{array}{l}23.1 \\
(8.30)\end{array}$ \\
\hline PANSS negative & $\begin{array}{l}34.76 \\
(7.20)\end{array}$ & $\begin{array}{l}33.36 \\
(6.36)\end{array}$ & $\begin{array}{l}32.14 \\
(6.16)\end{array}$ & $\begin{array}{l}31.16 \\
(4.78)\end{array}$ & $\begin{array}{l}29.74 \\
(7.53)\end{array}$ & $\begin{array}{l}24.3 \\
(8.66)\end{array}$ \\
\hline $\begin{array}{l}\text { PANSS general } \\
\text { psychopathology }\end{array}$ & $\begin{array}{l}78.44 \\
(16.50)\end{array}$ & $\begin{array}{l}76.02 \\
(14.30)\end{array}$ & $\begin{array}{l}74.9 \\
(13.24)\end{array}$ & $\begin{array}{l}72.78 \\
(15.09)\end{array}$ & $\begin{array}{l}70.42 \\
(15.78)\end{array}$ & $\begin{array}{l}67.32 \\
(10.93)\end{array}$ \\
\hline
\end{tabular}

Graph-14: Comparision of Mean Panss Score for Patients at Each Visit

P-VALUE $<0.0001^{\star \star *}$

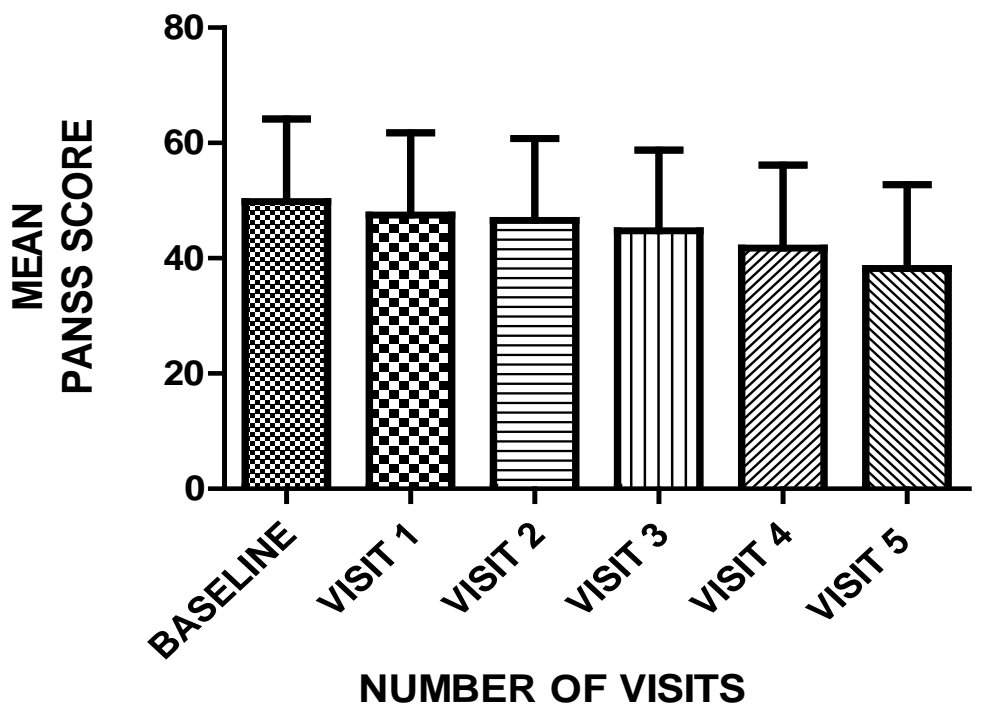

(C) The International Journal of Indian Psychology | 34 
Role of Clinical Pharmacist in Promoting Patient Compliance through Assessment of Reasons for NonCompliance and Minimum Maintenance Dose Titrations in Schizophrenic Patients

P-value was calculated by using two-way ANOVA. and the results are found to be statistically significant $\left(\mathrm{P}<0.0001^{* * *}\right)$

Table-18: Mean Panss Subscores ( Positive, Negative, General Psychopathology) for Seven Patients at Each Visit was Shown in the Table.

\begin{tabular}{|l|l|l|l|}
\hline \multirow{2}{*}{ Score, mean (SD) } & In treatment & \\
\cline { 2 - 4 } & BASE LINE & VISIT 1 & VISIT 2 \\
\hline PANSS positive & $34.85(5.58)$ & $42.14(3.38)$ & $47.28(0.95)$ \\
\hline PANSS negative & $28.5(8.07)$ & $31.85(7.92)$ & $45.42(1.51)$ \\
\hline PANSS general psychopathology & $67.71(14.16)$ & $87.57(11.34)$ & $103.28(3.25)$ \\
\hline
\end{tabular}

As measured using the PANSS, patients condition worsen by each visits. P-value was calculated by using two-way ANOVA and the results are found to be statistically significant $\left(\mathrm{p}-0.0013^{* *}\right)$

Graph-15: Comparision of Mean Panss Score for Seven Patients at Each Visit

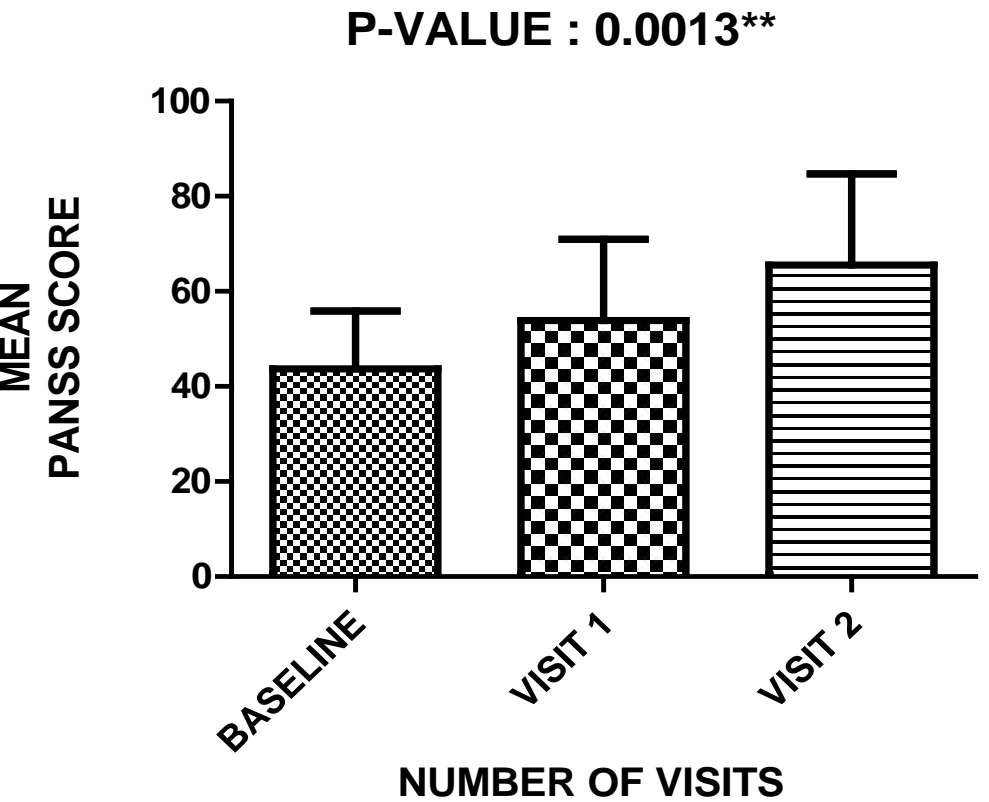

\section{DISCUSSION}

The study is an attempt to find out the rate of non-compliance and the attitudes and reasons, it also highlights the benefits of dose titration in schizophrenic patients. Medication adherence 
plays a vital role in patients who were diagnosed with schizophrenia. Negative attitude and poor insight may lead to development of non-adherence. Beck et al ${ }^{22}$,described a direct negative relationship between concerns regarding antipsychotic drugs and adherence and an indirect negative effect as a general disturbance regarding pharmacotherapy and adherence. The authors showed a medication effect between awareness of illness and perceived necessity of antipsychotic medication on adherence. Our study is compared with shakeel ansari et al ${ }^{23}$., for the variables affecting drug compliance in schizophrenic patients which shows $37 \%$ non compliance rate and ivatury sarath Chandra et al., ${ }^{24}$ Study shows $41.9 \%$ non compliance. Whereas our study shows high prevalence of non compliance. According to Esteban Medina et al., ${ }^{25}$ study a total of $74.4 \%$ shows compliance.

Most of the previous studies conducted at various regions of the world including India showed that substance abuse is a strong predictor of non compliance, which is a contradiction to present study. According to and Ivatury sarath Chandra et al., ${ }^{24}$ Study denial of illness was the most common reason leading to non compliance. Financial burden, lack of knowledge of illness, reduced access to treatment facilities, side effects of medication and substance abuse also stand for significant contributory reasons for non-compliance. In our study accesses to treatment problems, financial obstacles, no perceived daily benefit and forgetfulness were the main reasons for non compliance. According to rosa et $\mathrm{al}^{26}$ and Loffler et $\mathrm{al}^{27}$., the reasons for non compliance is mainly " inconvenience due to side effects" and "perceived daily benfit" was the reason for compliance. Statistically significant reasons for compliance and non-compliance was found by using ROMI scale. In our study the main reason for compliance was observed were relapse prevention, desire to be normal, fear of hospitalization, supervision. Where as shakeel ansari et al ${ }^{23}$., study shows positive relation with psychiatrist and perceived daily benefit are essential in improving compliance but according to ivatury sarath Chandra et al ${ }^{24}$., The factors contributing compliance were followed by positive family belief, relapse prevention and pressure or force by the family members. The point of concern coming out of these observations that there is high prevalence of non compliance to occur over compliance which is affects the management of schizophrenia. Evaluation of reasons for non compliance using the ROMI scale is mainly highlighted through five important reasons. They include

a) Patients who do not comply are likely to feel that their medications do not help as opposed to patients who comply with neuroleptics and are more likely to report feeling better.

b) Poor relationship with psychiatrist leading to poor compliance.

c) Poor insight was another factor.

d) The exponential factor is stigma related to schizophrenia.

e) The presence of any other effect of drug (eg; ADR, side effects) was also a factor for noncompliance. 


\section{Role of Clinical Pharmacist in Promoting Patient Compliance through Assessment of Reasons for Non- Compliance and Minimum Maintenance Dose Titrations in Schizophrenic Patients}

Moreover, the Clinical Antipsychotic Trials of Interventions Effectiveness (CATIE) study found that the degree of clinical improvement due to treatment and patient quality of life are factors also related to the attitude towards medication.

In our study there is no much difference in compliance among males and females in two groups which is more likely with the study ivatury sarath Chandra et al ${ }^{24}$ and concurrent with the previous findings diaz et al ${ }^{28}$.

Better compliance in employed population can be because patients suffering with schizophrenia have less chances of getting employed, which may leads to deterioration of the financial status of the family, which makes more prone to quit the course of medication. The difference was found to be statistically significant which is similar to Ivatury Sarath Chandra et al ${ }^{93}$ Study. It is also mostly nearer to the findings of Atwood et al ${ }^{29}$.,Who, in a compilation analysis of 86 studies involving 23,796 psychiatric patients had found a positive association between unemployement and non-adherence indicating financially poor affordable capacity in this population.

The mean age of onset of illness in compliant and non-compliant group (23.5+7.7) . The interruption that could be made for early onset of psychosis is prolong duration of the treatment which may leads to increased number of side effects leading to non-compliance. The other factors for burnt out syndrome in caregivers and increased financial burden with prolonged duration of illness in patients with early onset of psychosis. These findings are nearly to the findings of Ivatury Sarath Chandra et al ${ }^{24}$.the Balikci et al ${ }^{30}$ study which is a 2 yr prospective study found there was a high degree of noncompliance in patients with early onset of psychosis. The DAI is one of the most common measures used to assess attitude or adherence rating scales. Positive attitude towards medication, as measured by the DAI is associated with significantly higher adherence rates. The attitude towards treatment in patients has been additionally related to factors such as employment status, duration of untreated schizophrenia, disease severity, treatment response, hospital profile and therapeutic alliance with the medical staff.

The overall mean score of DAI was higher $(6.08 \pm 2.02)$ in patients who were compliant than the non-compliant group. These findings were similar to that of Ivatury Sarath Chandra et al ${ }^{24}$ Study. This may be due to the high positive belief in treatment and medication of family members might be the reasons for the positive attitude of patient and compliance towards medication. The DAI is one of the most common measures used to assess attitude or adherence rating scales. Positive attitude towards medication, as measured by the DAI, was associated with significantly higher adherence rates. The attitude towards treatment in outpatient has been additionally related to factors, such as employement status, duration of untreated psychosis (DUP). disease severity, treatment response, hospital profile, and therapeutic alliance with the

medical staff. Kyoko higashi et al ${ }^{31}$., Dose titration can also be problematic in clinical practice in terms of optimal number of dosage decrease steps and the time required to reach adequate efficacy and provide the required therapeutic effect. However, different titration schedules may be needed for drugs depending upon respective half-lives. Adequate dosing varies from patient 


\section{Role of Clinical Pharmacist in Promoting Patient Compliance through Assessment of Reasons for Non- Compliance and Minimum Maintenance Dose Titrations in Schizophrenic Patients}

to patient and depends upon severity and chronicity of illness, susceptibility to adverse effects. Switching of drugs is also done depending upon the patient response.

When comparing the results regarding the duration of illness in years, it was found that in cecilia brain ${ }^{83}$ et al study, 13 are having duration of illness between 0-5,20 are having between 6-10,16 are having the schizophrenia form the past 11-15 years and majority of the study participants i.e.,63 are suffering with the illness from more than 15 years. whereas in current study,23 are having duration of illness between 0-5,35 are having between 6-10,18 are having the schizophrenia form the past 11-15 years and majority of the study participants i.e.,31 are suffering with the illness from more than 15 years.

In our study,34 are having 1-2 exacerbations,32 have experienced 3-5 exacerbations,29 with 6-9 and 12 subjects are having $>9$ exacerbations. these results are correlated with the cecilia brain ${ }^{83}$ et al study in which it was observed that 14 are having 1-2,33 experienced 3-5,25 suffer with 6-9 and 40 subjects have experienced $>9$ exacerbations.

The Mean PANSS subscores (positive, negative, general psychopathology) In the present study was compared with the results of Haya Ascher-Svanum ${ }^{32}$ et al study and is found that the illness severity had improved.

The cecilia brain ${ }^{33}$ et al study shows a mean of 14 subjects $(n=81)$ in the adherent group and 2 subjects in the non adherent group $(n=31)$ were using first generation antipsychotics.but in present study $72 \%$ of the non adherent patients and $63.15 \%$ subjects in adherent group were on first generation antipsychotics. In The cecilia brain ${ }^{33}$ et al study,out of 112 outpatients,16.1\% have paranoid schizophrenia and $41.1 \%$ have undifferentiated schizophrenia,9.8\%-residual schizophrenia.in our study $64 \%, 2 \%$ and $4 \%$ subjects in Group-A were suffering with paranoid,undifferentiated and residual schizophrenia respectively.and 71.92\%,5.26\% and 1.75\% were suffering with paranoid,undifferentiated and residual schizophrenia in Group-B. In present study ,39.2\% of subjects were using haloperidol and $28.03 \%$ were on medicaion chlorpromazine and $77.5 \%$ were on olanzapine and $62.6 \%$ were taking risperidone the results were compared to the cecilia brain ${ }^{33}$ et al study $(n=112)$ in which the Antipsychotic medications were monitored across the study period and was found that number of patients taking haloperidol was 5.4\%,olanzapine-21.4\% and risperidone-15.2\%.Total Number of patients on olanzapine and risperidone who received the maximum doses were $90.3 \%$ and $71.6 \%$ is compared with CATIE study (peter f.buckley ${ }^{34}$ et al) which shows $40 \%$ of patients are receiving the maximum dose for both the drugs. Discontinuation rates in our study are compared with the CATIE (the clinical antipsychotic trials of intervention effectiveness) Study. The discontinuation rate of olanzapine because of lack of tolerability was found to be $13.2 \%$ which shows decreased percentage (19\%) when compared to CATIE study. the discontinuation rate of risperidone was $22.3 \%$ which shows increased percentage (10\%) when compared to CATIE study.In our study,the discontinuation rate because of lack of efficacy of olanzapine and risperidone was found to be 
$8.43 \%$ and $19.4 \%$ respectively ,which was compared to CATIE study in which olanzapine was discontinued at a rate of $15 \%$ and risperidone at $27 \%$.

\section{CONCLUSION}

By assessing the reasons for non-compliance, administering the tailored doses and providing the patient education, rational therapy with increased safety and efficacy was provided to the individual patients which increases the patients quality of life and prevents the risk of relapse as well as higher economic costs for patient care.

Compliance is highly influenced by benefit with medications and positive relationship with the psychiatrists. Therefore psychiatrists should maintain a good therapeutic relationship with the schizophrenic patients.

Family pressure on the subjects for taking medicines increases compliance suggesting a need for psychoeducation to family members.

\section{REFERENCES}

1. Joseph T Dipiro, Robert L Talbert, Gary C Yee ,Gary R Matzke, Barbara G Wells, L Michael Posey. Pharmacotherapy - A pathophysiologic approach. $7^{\text {th }}$ Ed. Newyork: Mcgraw Hill . 2008; 1099-116.

2. Byrne N, Livingston G. \& Regan C. Adherence to treatment in mood disorders. Curr. Opin Psychiatry, 2006; 44-49.

3. Battaglia, J. Compliance with treatment in schizophrenia. American psychiatric association $-53^{\text {rd }}$ Institute On Psychiatric Services.2006.

4. Cramer J and R. Rosenheck."Compliance with medication regimes for mental and physical disorders." 1998; 49: 196-201.

5. Acosta FJ, Hernández JI, Pereira J, Herrera J, Rodríguez CJ. Medication adherence in schizophrenia. World J Psychiatr 2012; 2(5): 74-82.

6. Bond CA, Salinger RJ. Fluphenazine Outpatient Clinics: A Pharmacists Role. J Clin Psych, 1979; 40:501-3.

7. Saklad SR, Ereshefsky L, Jann MW, Crismon ML. Clinical pharmacists impact on prescribing in an acute adult psychiatric facility. Drug Intell Clin Pharm, 1984; 18:632- 4.

8. Lobeck F, Traxler WT, Bobiner DD. The cost-effectiveness of a clinical pharmacy services in an outpatient mental health clinic. Hosp Community Pharm, 1989;40(6):6435.

9. Finley PR, Rens HR, Pont JT. Impact of a collaborative pharmacy practice model on the treatment of depression in primary care. Am J Health Syst Pharm, 2002; 59:1518-26.

10. Finley PR, Crismon ML, Rush AJ. Evaluating the impact of pharmacists in mental health; A systemic review. Pharmacotherapy, 2003; 23(12):1634-44.

11. Bultman DC, Svarstad Bl; effects of pharmacist monitoring on patient satisfaction with anti-depressant medication therapy. J Am pharm Assoc, 2002; 42:36-43.

12. Rickles NM, Savarstad BL, Statz-Paynter J, Taylor LV, Kobak K. Pharmacists' telemonitoring of antipsychotic use: effects on patient feedback and other outcomes. $\mathrm{J}$ Am Pharm Assoc, 2005; 45(3):344-53. 
13. Rickles NM, Savarstad BL, Statz-Paynter J, Taylor LV, Kobak K. Improving patient feedback regarding antidepressant treatment: an experiment in eight community pharmacies. J Am Pharm Assoc, 2006; 46(1):25-32

14. Davanzo J, Dobson A, Koenig L, Book R. Medication therapy management services: a critical review. American pharmacists association; Washington, Dc, USA: 2005.

15. Gable K, Stunson M. clinical pharmacist interventions on an assertive community treatment team.Community ment. Health J. 2010; 46:351-355.

16. Canales PL, Dorson PG, Crismon ML, Canales PL, Dorson PG, Crismon ML. Outcomes assessment of clinical pharmacy services in a psychiatric inpatient setting. Am J Health Syst Pharm .2001; 58:1309-1316.

17. Valenstein M, Kavanagh J, Lee T, Reilly P, Dalack G.W, Grabowski J, Smelson D, Ronis DL, Ganoczy D, Woltmann E. using a pharmacy-based intervention to improve antipsychotic adherence among patients with serious mental illness. Schizophr Bull. 2011; 37:727-736.

18. Barnes TR, Paton C. antipsychotic poly pharmacy in schizophrenia: benefits and risks. CNS Drugs.2011; 25:383-399.

19. Oreilly CL, Bell JS, Chen TF. Consumer-led mental health education for pharmacy students: impact on stigma and attitudes towards provision of pharmaceutical services. Am J Pharm Educ . 2010;74.

20. Nishtala PS, Mclachlan AJ, Bell JS, Chen TF. Psychotropic prescribing in long-term care facilities: impact of medication reviews and educational interventions. Am J Geriatr Psychiatry. 2008; 16:621-632.

21. Richardson TE, O'reilly CL, Chen TF. A comprehensive review of the impact of clinical pharmacy services on patient outcomes in mental health. Int J Clin. Pharm. 2013; 36:222-232.

22. Beck EM, Cavelti M,Kvrgic S, Kleim B, Vauth R . Are we addressing the "right stuff” to enhance adherence in schizophrenia ? understanding the role of insight and attitude towards medication .Schizophr Res.2011; 132:42-49.

23. Shakeel Ansari, Shakila Mulla; Analysis Of Variables Affecting Drug Compliance In Schizophrenia: Industrial Psychiatry Journal,2014; 23(1):58-60.

24. Chandra IS, Kumar Kl, Reddy MP, Reddy CP. Attitudes toward medication and reasons for non-compliance in patients with schizophrenia. Indian J Psychol Med 2014 ; 36:2948.

25. Esteban Medina,Joan Salvà,Rubén Ampudia,Jorge Maurino,Juan Larumbe. Short-term clinical stability and lack of insight are associated with a negative attitude towards antipsychotic treatment at discharge in patients with schizophrenia and bipolar disorder:Dove Press Journal,Patient Preference and Adherence, 28 August 2012.

26. Rosa MA, Marcolin MA, Elkis H. Evaluation of the factors interfering with drug treatment compliance among brazilian patients with schizophrenia. Rev Bras Psiquiatr 2005; 27:178-84.

27. Loffler W, Killan R, Toumi M, Angermeyer MC. Schizophrenic patients subjective reasons for compliance and non compliance with neuroleptic treatment .Psychiatr Serv 2004; 55:174-9.

28. Diaz E, Neuse E, Sullivan MC, Pearsall HR, Woods SW. Adherence to conventional and atypical antipsychotics after hospital discharge ,J Clin Psychiatry 2004;65:354-60. 
29. Atwood N, Beck JC. Service and patient predictors of continuation in clinic based treatment.Hosp Community Psychiatry 1985; 36:865-9.

30. Balikci A, Erdem M, Zincir S, Bolu A, Bozkurt A, Sarper E. Adherence with outpatient appointments and medication : a two year prospective study of patients with schizophrenia. Bull Clin Psychopharmacol 2013; 23:57-64.

31. Kyoko Higashi, Goran Medic, kavi J , Little Wood, Teresa Diez, Ola Granstrom, and Marc dehert. Medication adherence in schizophrenia:factors influencing adherence and consequences of non adherence, a systematic literature review.ther adv psychopharmacol.2013; 3(4) : 200-218.

32. Haya Ascher-Svanum, Peter Weiden , Allen W Nyhuis, Douglas E. Faries , Virginia Stauffer , Sara Kollack-Walker , Bruce J Kinon. Early perception of medication benefit predicts subsequent antipsychotic response in schizophrenia: "the consumer has a point" revisited .Clinical Schizophrenia \& Related Psychoses Summer 2014.

33. BrainC.Drugattitudeandotherpredictorsofmedicationadherenceinschizophrenia:12months of Electronic Monitoring (MEMSS). European neuropsychopharmacology(2013).

34. Peter FB , Christoph UC. Strategies for dosing and switching antipsychotics for optimal clinical management. J clin psychiatry. 2008; 69(1):4-17. 